\title{
أسلوب جون طوهسون فى تعليم عزف آلة البيانو للمبتدئين الكبار والاستفادة منه لطلاب التربية الموسيقية قونية
}

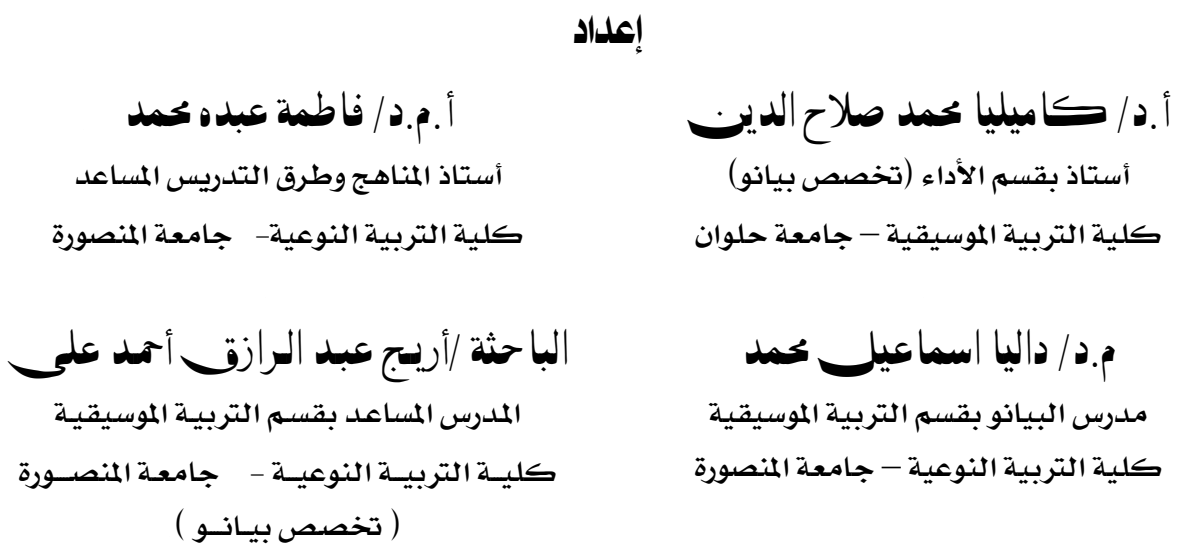

إعداد

أ.م.دم/ فاطمة عبده محمد أمدئ

أستاذ المناهج وطرق التدريس المساعد

كلية التربية النوعية- جامعة المنصورة

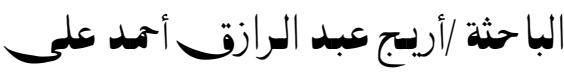

المدرس المساعد بقسهم التربية الموسيقيـة المبل

كليـة التربيـة النوعيـة - جامعـة المنصــورة

( تخصص بيـانـو )

أ.د / كباميليا محمد صلاح اللدير.

أستاذ بقسم الأداء (تخصص بيانو)

كلية التربية الموسيقية - جامعة حلوان الهداء لحسيان

مدرس البيانو بقسم التربية الموسيقية

كلية التربية النوعية - جامعة المنصورة

مجلة بحوث التربية النوعية ـ جامعة المنصورة

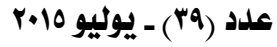




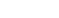




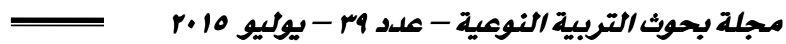

\title{
أسلوب جون طوهسون فى تمليم عرنف آلة البيانو للمبتدئين الكبار والاستفادة هنه لطلاب التزبية الموسيقية
}

\author{
إعداد \\ ** أ . م.د/ فاطمة عبدهمحمد

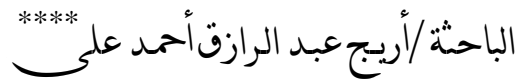

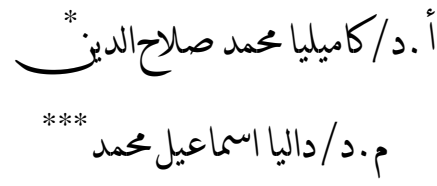

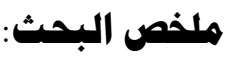

تتناول الباحثة هذا البحث بغرض إيجاد دراسة علمية فنية قد تسهـم فى الوصول إلى أفضل

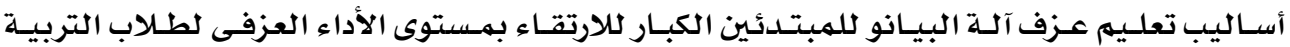

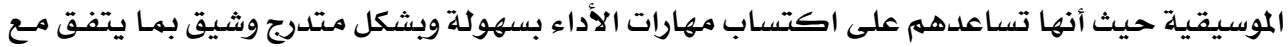

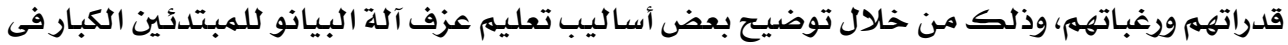

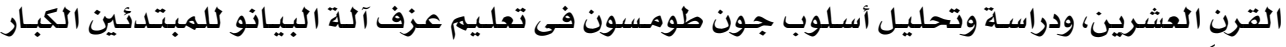

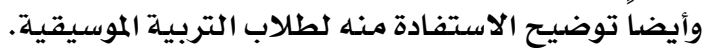

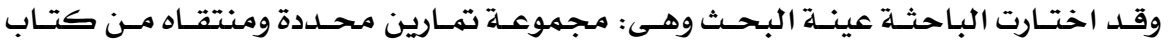

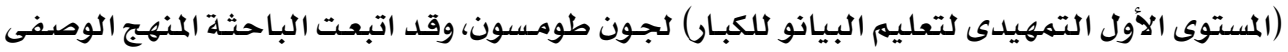

$$
\text { (تحليل محتوى) (المستوى الاول }
$$

\section{• وقد توصلت الباحثة إلى النتائج التالية:}

ا- حلدت الباحثة بعض أساليب تعليهم عزف آلة البيانو للمبتدئين الكبار فى القرن العشرين وأهم ما

$$
\text { يميز كل منها. }
$$

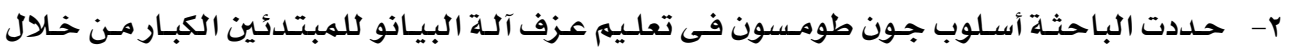
الدراسـة والتحليل العزفى لعينة البحثث.

r- حددت الباحثة الاستفادة من أسلوب جون طومسون فى تعليهم عزف آلـة البيـانو للمبتـدئين الكبـار لطلاب التربية الموسيقية.

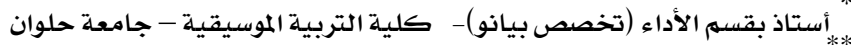

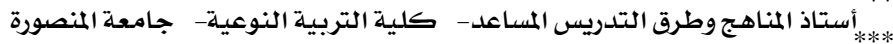

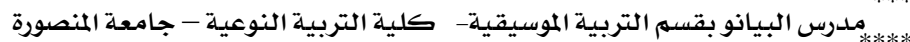

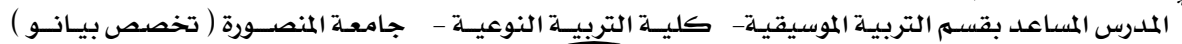


تعتبر دراسـة آلة البيانو من أهم الأسس التى لا غنى عنها فى الدراسـة الموسيقية حيث أنها

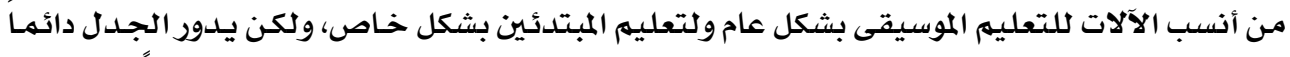

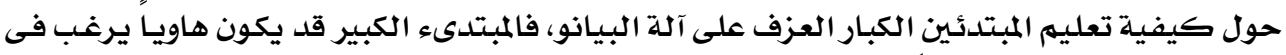

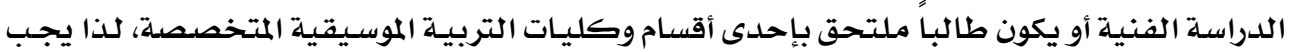

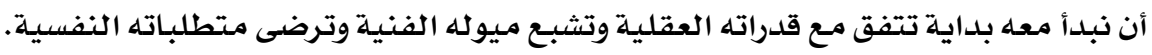

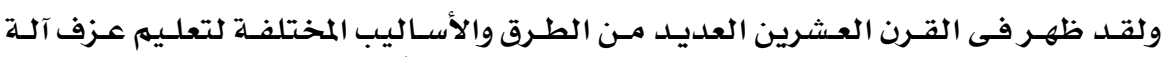

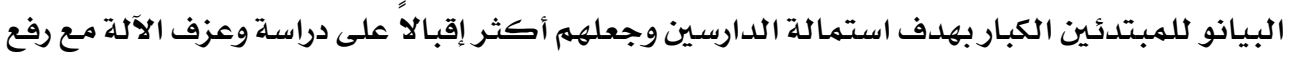
مستوى أدائهم فى وقت قصير بشكل تدريجى يصلى يصل بهم إلى التعلهم دون نفور أو ملل.

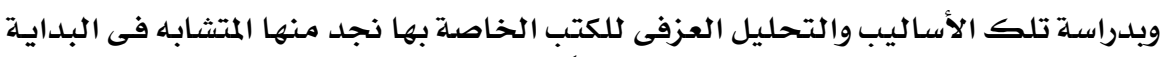

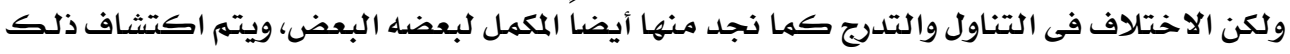

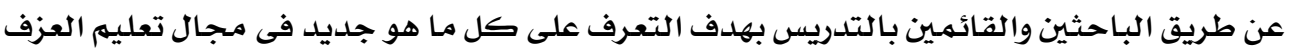

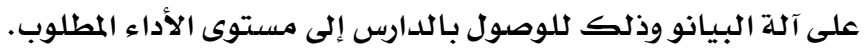

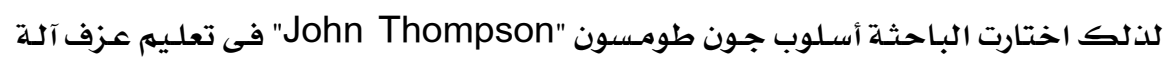

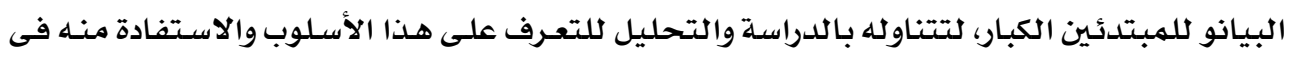

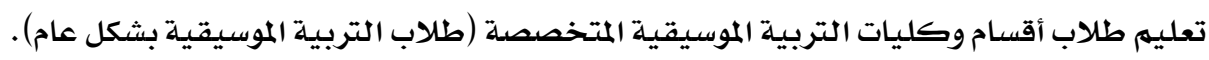

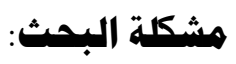
لاحظت الباحثة عدم استخدام الكتب الخاصـة بتعليم المبتدئين الكبـار فى تعليهم عزف آلـة

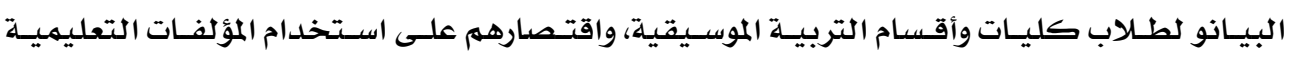

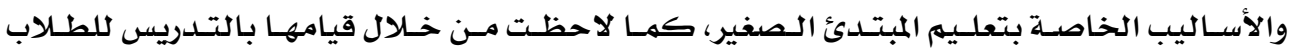

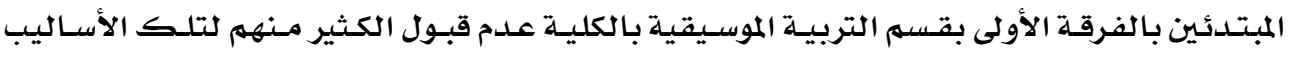

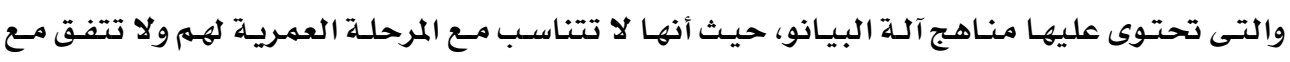

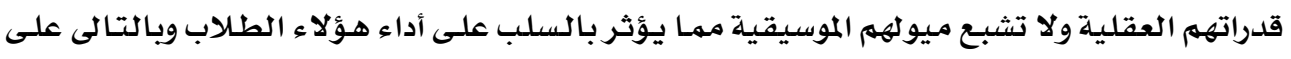

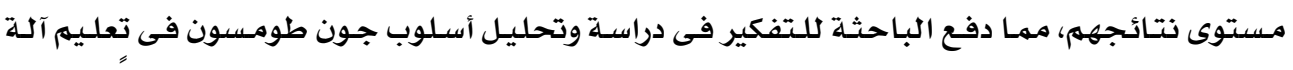

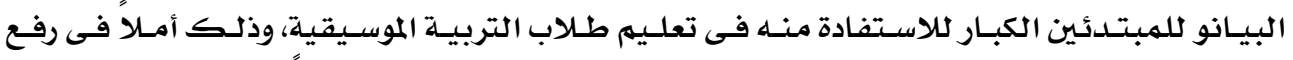

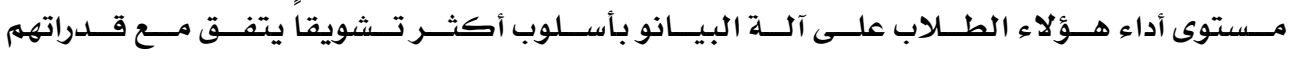
ورغباتهم وميولهمه.

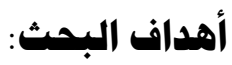
1- توضيح بعض أساليب تعليم عزف آلة البيانو للمبتدئين الكبار فى القرن العشرين. r- توضيح أسلوب جون طومسون فى تعليهم عزف آلة البيانو للمبتدئين الكبار. 


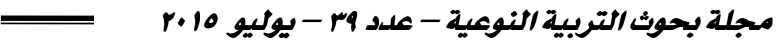

r- توضيح الاستفادة من أسلوب جون طومسون فى تعليه عزف آلة البيانو للمبتدئين الكبار لطلاب

التربية الموسيقية.

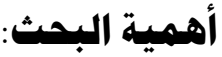

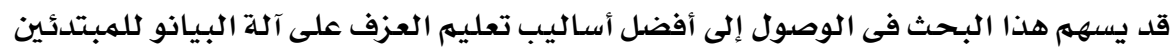

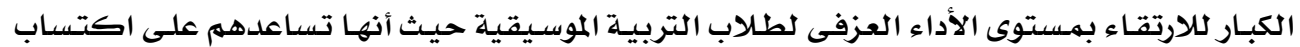

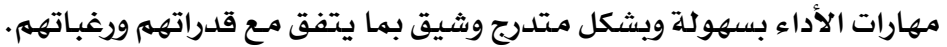

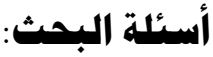

1- ما أساليب تعليه عزف آلة البيانو للمبتدئين الكبار فى القرن العشرين؟

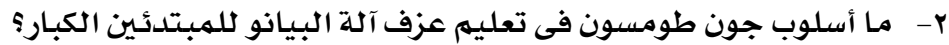

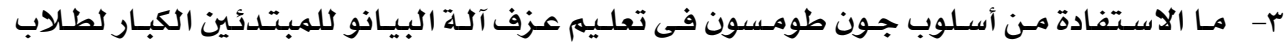

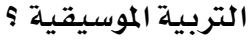

هدود البمث:

يقتصر هـذا البحـث على كتـاب ( المستوى الأول التمهيـدى لتعلسيم البيـانو للكبـار ) لجـون

" The Adult Preparatory Piano Book "

طومسون والذى أعده عام بـ 19 ام

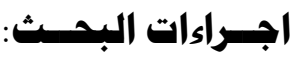

وتشتمل على:

• منهج البحث:

يتبع هذا البحث المنهج الوصفى (تحليل محتوى).

• عينة البحث: - ميث:

مجموعة تمارين محددة ومنتقاه من كتاب (المستوى الأول التمهيدى لتعليم البيانو للكبار)

" The Adult Preparatory Piano Book "

لجون طومسون

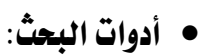

المدونات الموسيقية الخاصسة بالتمـارين المنتقـاه مـن كتاب (المستوى الأول التهميدى لتعليم

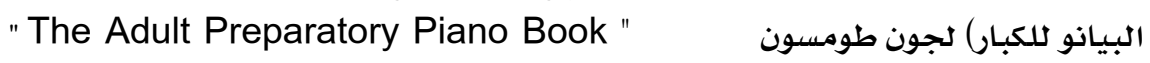




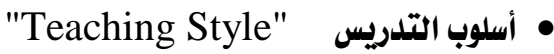

يقـصلد بـه (الكيفيـة) فهـو طريقــة المعلسم فـى التعامـل مـع الموقـف التعليهـى والتـى تظهـر

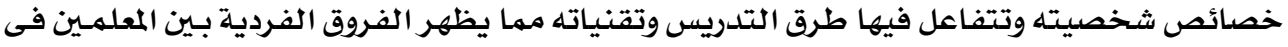

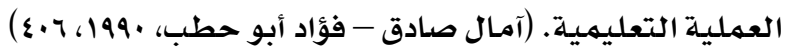

"Expression" التعبير

هـو الأداء بطريقـة معـبرة عـن الأحساسـيس والعواطف والانفعـالات أثنـاء العـزف، وذلكـ مـن

خـلال بعض المصطلحات الموسـيقية التى تكسب المؤلفـة طابعها الخـاص بها، بالإضـافة إلى استخدام

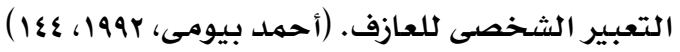

"Technique" التكنيك

هى المهارة العزفيـة الدلازمسة للسيطرة على جميع عضلات الجسمى المستخلدمة أثناء العزف.

(Cooper, Martin, 1975, 159)

"Skill" المهارة

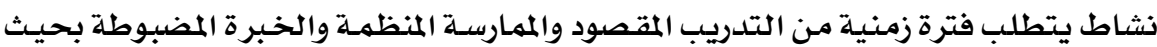

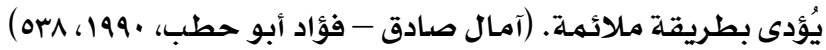

"Accompaniment" المصاحبة

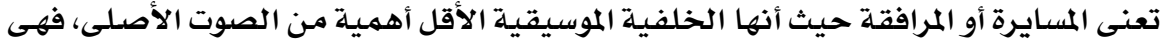

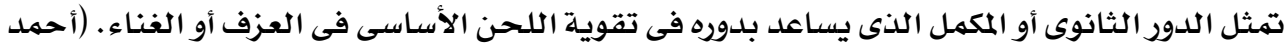

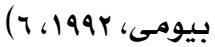

\section{الدراسات والبحوث البابقة المرتبطة بموضوع البمث:}

قامت الباحثة بالإطلاع على الدراسـات العربية والأجنبية السـابقة المرتبطة بهوضـوع البحث الراهن، ثم قامت بتصنيفها لمحورين:

- المحور الأول: دراسات تناولت بعض أساليب تعليم عزف آلة البيانو للمبتدئين الكبار فى القرن

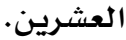

- م المحور الثانى: دراسات تناولت أسلوب جون طومسون فى تعليهم عزف آلة البيانو. 


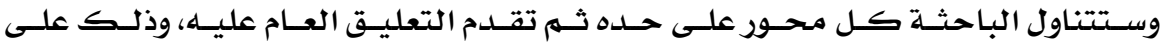

النحو التالى:

• أواً: دراسات تناولت بعض أساليب تعليم عزف آلة البيانو للمبتدئين الكبار فى القرن العشرين:

(1) (1994) (1راسة سوزان أحمد عسل (1) (1)

\section{بعنوان: " دراسة مسحية لتعليم آلة البيانو للمبتدئين الكبار "}

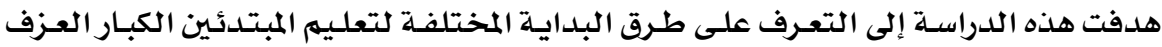

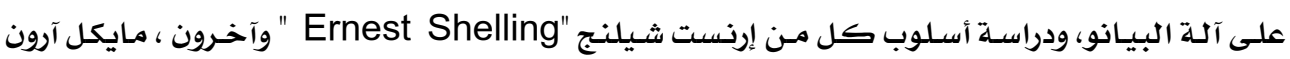

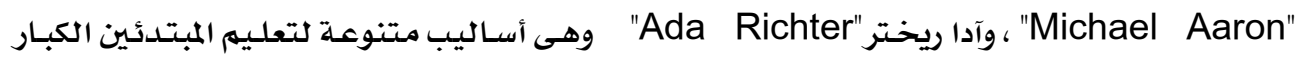

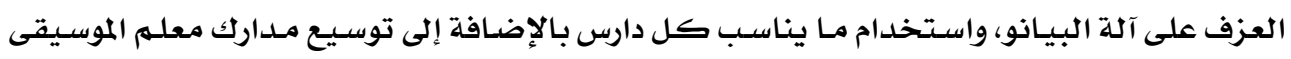

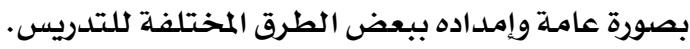
وقد اتبعت الباحثة المنهج الوصفى (تحليل محتوىى)، وتوصلت مـن خـلال الدراسـة إلى أوجـهـ

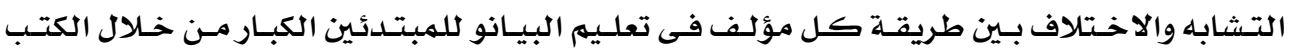
الثلاثة المختارة.

\section{(r) دراسة سماح خلف محمود أحمد (r.r)}

بعنوان: " طريقة كارل أورف فى تعليم عزف آلة البيانو للمبتدئين - دراسة تحليلية عزفية"

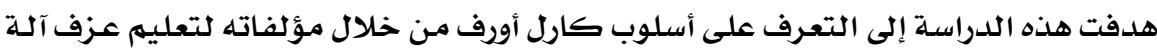

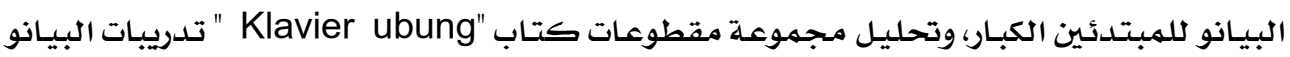

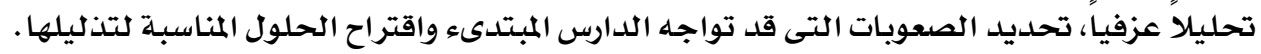

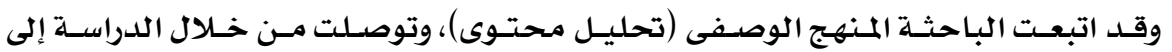

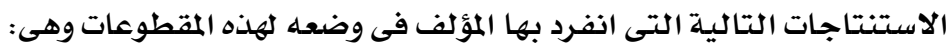

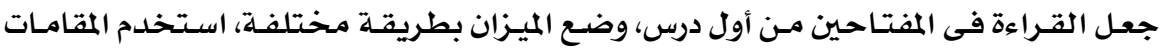

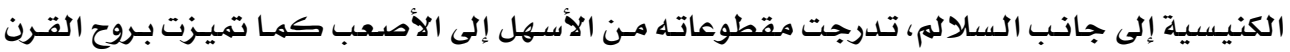

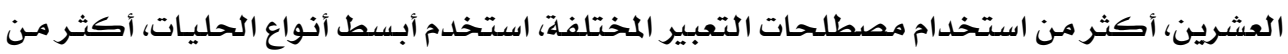

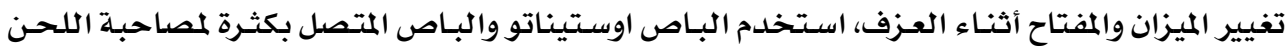

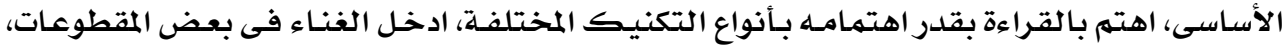
كرر كل هدف عدة مـرات فى ألحان وإيقاعات مختلفة اهنة. تعليـق عـام على الدراسات السابقة التى تناولت بعض أساليب تعليم عزف آلة البيانو للمبتدئين الكبار فى القـرن العشريـن: 
يتضـح مـن العرض السابق لأهداف ونتائج تلـك الدراسـات أنها تتفق مـع البحـث الراهن فى في

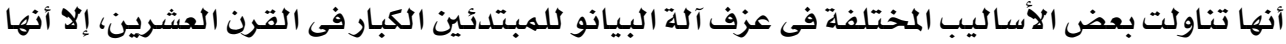

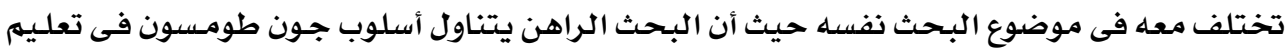
عزف آلة البيانو للمبتدئين الكبار والاستفادة منه لطلاب البحت التربية الموسيقية. • ثانياً: دراسات تناولت أسلوب جوز طومسوز فى تعليم عزف آلة البيانو:

(r) Dibble, Cameron Shawn دراسة (1992)

\section{بعنوان " جون سيلفانوس طومسون: عازف البيانو، المعلم، المؤلف "}

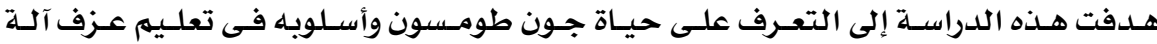
البيانو للأطفال.

وقد توصلت تلك الدراسلة إلى تحديد أسلوب جـون طومسون وفلسفته القائلـة: بأن تـدريس

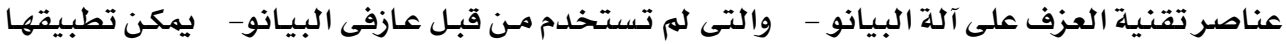

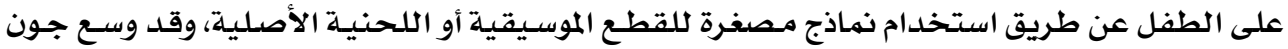

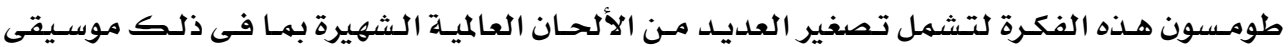

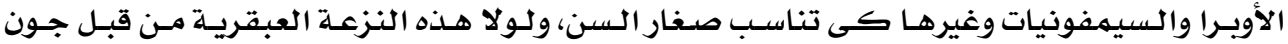

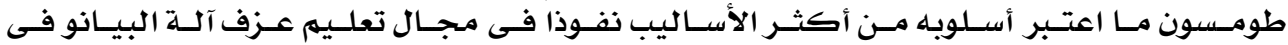
القرن العشرين.

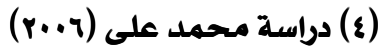

\section{بعنوان: " تحسين القدرة التكنيكية والتعبيرية لأطفال مركز الإشعاع الموسيقى}

بكلية التربية الموسيقية من خلال بعض دراسات جون طومسون سيلفانوس "

هدفت هذه الدراسلة إلى ترغيب الأطفال فى مؤلفات الدراسـات وإكسابهم المهارات التكنيكيـة والتعبيرية اللازمة على آلة البيانو من خلال بعض دراسات جون طومسون.

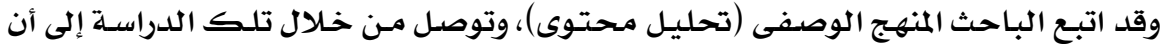
تحليل العناصر الموسيقية فى هذه الدراسـات عينة البحث من حيث ( الطول البنائى - السلهم - الميززان

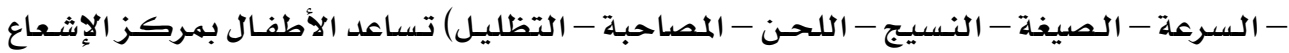
على التعرف على خصائصها الفنية والهدف منها وذلك لكلإرتقاء بمستوى أدائهم فى العزف. تعليــق عـام على الدراسات التى تناولت أسلوب جون طومسون فى تعليم عزف آلة البيانــو:

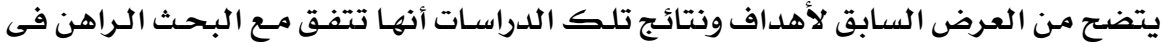

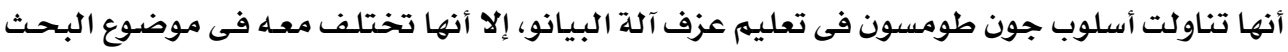




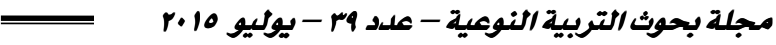

نفسـه حيـث أن البحـث الـراهن يتنـاول أسـلوب جـون طومسسون في تعليهم عزف آلـة البيـانو للمبتـدئين الكبار والاستفادة منه لطلاب التربية الموسيقية.

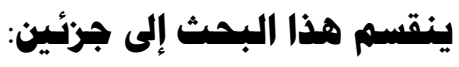

•

$$
\text { ويشتمل على مبحثين: }
$$

• المبحث الأول: بعض أساليب تعليم عزف آلة البيانو للمبتدئين الكبار في القرن العشرين. • المبحث الثانى: نبذة عن "جون طومسون" وأسلوبه وأهم أعماله.

\section{ثانياً: الإطار التطبيقى:}

ويتناول دراسة وتحليل أسلوب جـون طومسون فى تعليهم عزف آلـة البيانو للمبتدئين الكبـار

والاستفادة منه لطلاب التربية الموسيقية.

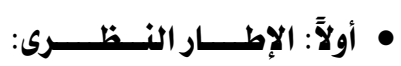

• المبحث الأول: بعض أساليب تعليه عزف آلة البيانو للمبتدئين الكبار فى القرن العشرين:

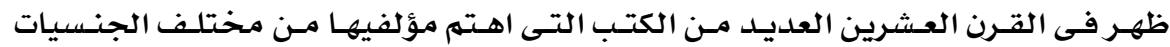

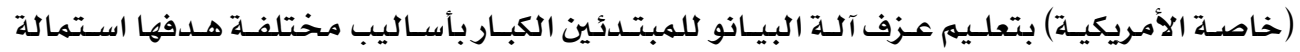

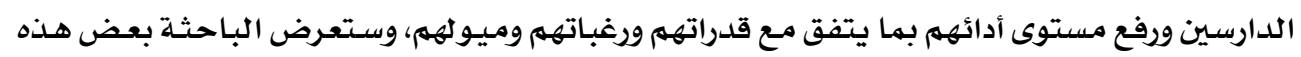

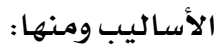

\section{(1) (1) أسلـوب مايكل آرون "Michael Aaron"}

* تميز أسلوب مايكل آرون فى تعليه عزف آلة البيانو للمبتدئين الكبار بأنه:

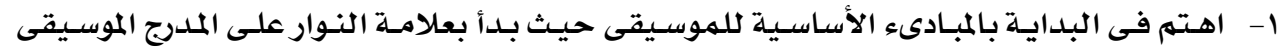

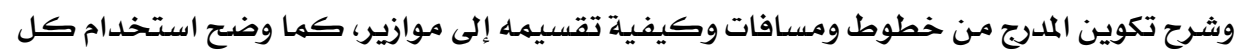

$$
\text { من مفتاحى (صول، فا ). }
$$

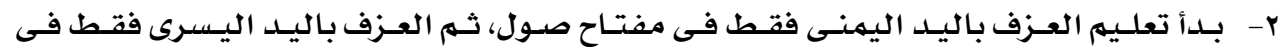
مفتاح فا.

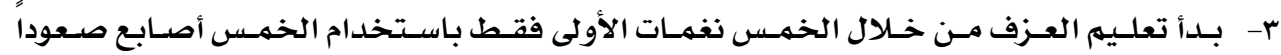
وهبوطاً من دو الوسطى.

ع- اهتم بكتابة ترقيم الأصابع على النغمات.

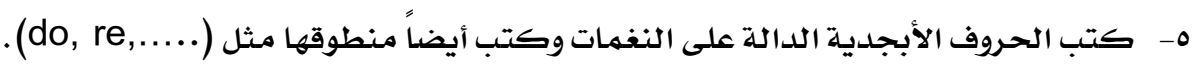




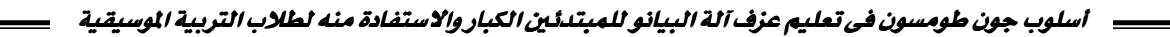
ج- استخدم الموازين المختلفة كها استخدم الإيقاعات البسسيطة، ووضـع التـدوين الإيقـاعى الخـاص بكل مقطوعة أعلاها كى يصفقه الدارس ويتدرب عليه قبل أداء المقطوعة.

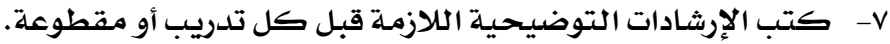

^- عليهم عزف اليدين معاً فى البداية عن طريق تبادل اليدين على المفتاحين (صول، فا ). 9- عند شـرح كل معلومـة جديدة كان يضع لها تمـرين أو مقطوعة للتدريب عليها.

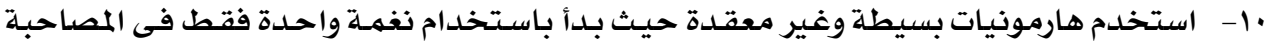

$$
\text { فى البدايلة. }
$$

ال - استخلـم الألحان الشعبية كما أعاد صسياغة الألحـان الكلاسيكية والرومانتيكيـة لبعض أعمـال مـؤلفين مـخـلفـين مثـل (بيتهـوفن - تشايكوفسكى - شـوبيرت - برامـز - ذيسـت)، كمـا وضـع بعض المقطوعات الخاصة من تأليفه. rا - ألحانه سلسـة وبسيطة وملائمسة للدارس المبتدىى فهى تجـذب المبتـدئين لتعلهم عزف آلـة البيـانو بأسلوب شيق بعيدا عن الملل. rا- بلدأ التدريب فى سلهم دو الكبير ثم انتقل إلى سلهم صول الكبير. ع ا- اهتم بشرح السلا لم الكبيرة فقط وتدوينها على المدرج الموسيقى حيث أضاف صفحات للسـلالم فى نهاية الكتاب.

10- شرح الرياط الزمنى والرباط اللحنى، كما استخدم علامسة الإطالة (الكورونا) والمازورة الناقصة

$$
\text { (الأناكروز) (تشرح) }
$$

$$
17 \text { - شرح العزف المتصل والمتقطع والتدريب عليه. }
$$

IV - استخلدم التآلفات المفرطة والهارمونية كها شرح التآلفات الثلاثية وانقلاباتها. 1^- شرح الخطوط الإضـافية على المدرجـين مـع تفسير النغمات، كما أنه استخلدم تغيير المفاتيح فى المقطوعة الواحدة.

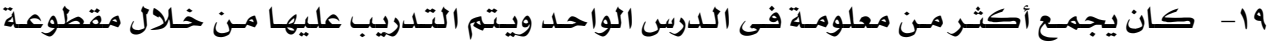
واحلدة، فعلى سبيل المثال أنه اسـتخدم علامـات التحويـل ( الرفـع والخفض) والخطـوط الإضـافية

$$
\text { والتآلفات فى مقطوعة واحدة. }
$$

•r- - اهتم بتعليهم القراءة الوهلية وشرحها بطريقة مبسطة تناسب الدارس المبتدىى.

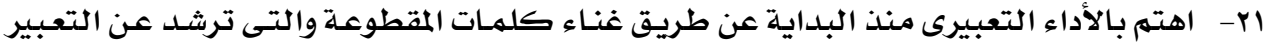

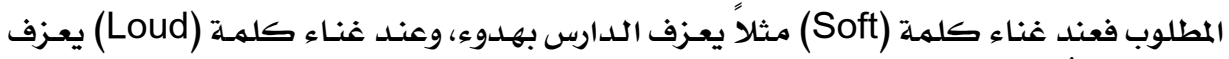
بشلدة وأيضضا أضـاف قـاموس فى نهايـة الكتاب لتفسير تلـك المصطلحات التعبيريـة، كهـا كـان يكتب السرعات فوق المقطوعات. Y - - اعطى تمارين تكنيكية لإكسـاب الأصسابع المهارة العزفية. 


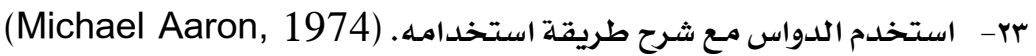
(ץ) أسلـوب جـون شـاوم "John Schaoum"

* تميز أسلوب جون شاوم فى تعليه عزف آلة البيانو للمبتدئين الكبار بأنه:

$$
\text { 1- بدأ بتعليم الوضع الصحيح لليدين والترقيم الخاص بالأصابع. }
$$

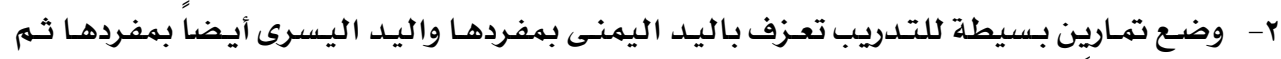

r- استخدم عدداً قليلاً من النغمات في كل تمرين مـع إيقاعات بسيطة.

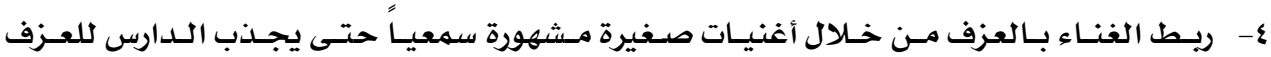

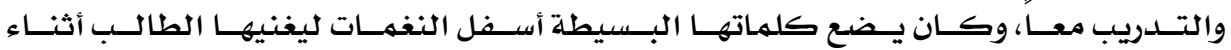

$$
\text { الأداء العزفى. }
$$

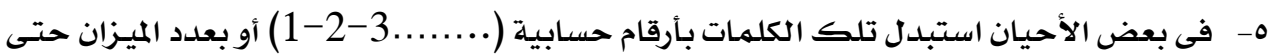
يتدرب الدارس على الإحساس بالزمن فى الإيقاع أثناء الإس الأداء.

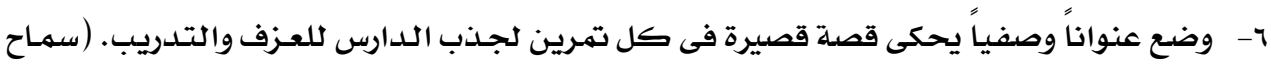

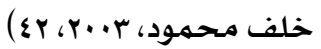

\section{:"Ada Richter" أسلـوب أدا ريـختر}

• ثميزت أدا ريختر بأسلوبها فى تعليهم عزف آلة البيانو للمبتدئين الكبار بأنها :

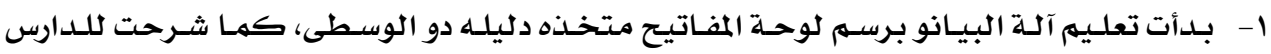

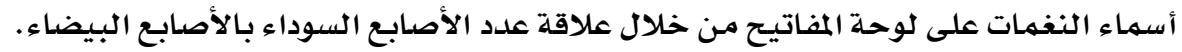

$$
\text { r - اهتمت بوضع اليدين على المفاتيح من البداية. }
$$

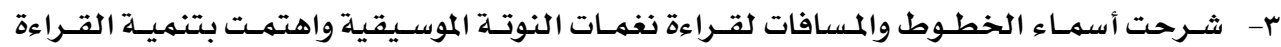
الوهلية منذ البداية أيضاً.

ع- شرحت العلامات الإيقاعية والسكتات بأزمنتها كما وضحت الموازين المختلفة. ه- بدأت بنغمات مفردة بالتبادل بين اليدين ثم نغمات مفردة مع مصاحبة هارومونية.

$$
\text { ج- استخدمت العزف المتصل والمتقطع مـع الشرح. }
$$

V- استخدمت التآلفات المفرطة وا لهارمونية كما شرحت التآلفات الثلاثية بانقلاباتها. ^- بـدأت التـدريب فى سـلهم دو الكبير كمها اسـتخدمت السلهم الصغير الطبيعى بعـد شـرحه، كما وضعت صفحات للسلالهم. 9- شرحت علامات الخفض والرفع وأعطت مقطوعات للتدريب عليها. 
• ا- استخدمت أغانى من شعوب مختلفة كما وضعت مقطوعات من تأليفها. 11- شرحت الرياط الزمنى والرياط اللحنى، كما استخدمت المرجعات وعلامـة الإطالة (الكورونـا )

$$
\text { والمازورة الناقصة (الأناكروز). }
$$

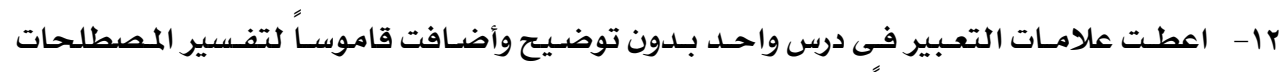

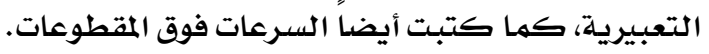

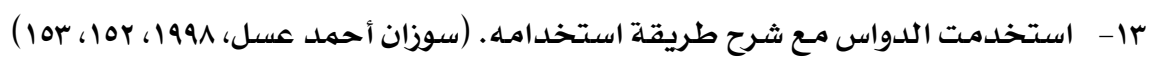
• المبحث الثانى: نبذة عن "جون طومسون" وأسلوبيه وأهم أعماله: - -

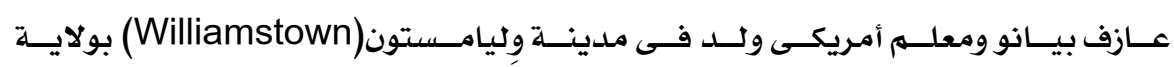

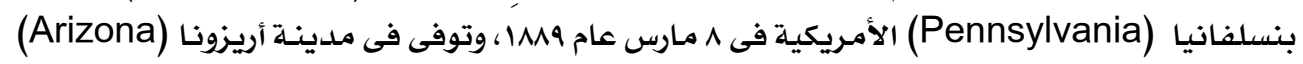

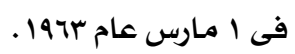

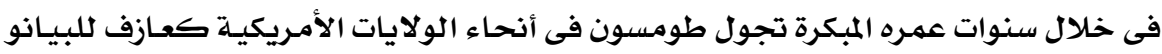

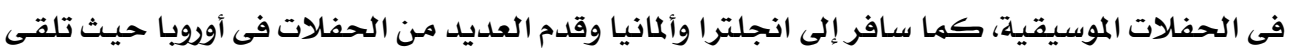

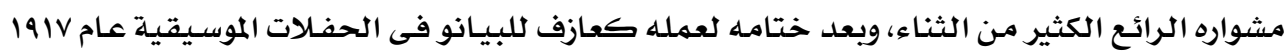

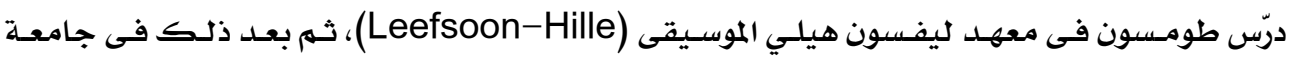

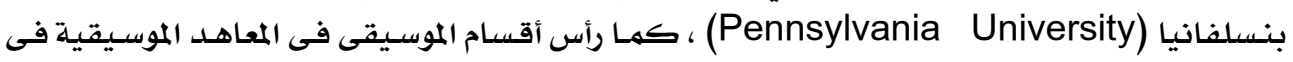

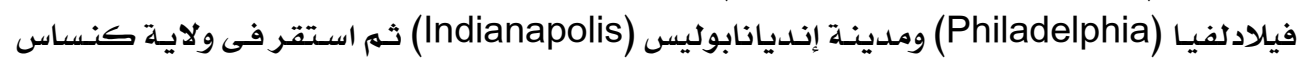
(Kansas) وخلال هذه الفترات طوّر طومسون بعض الأفكار الواضحة والأصلية فى تدريس آلـة البيانو،

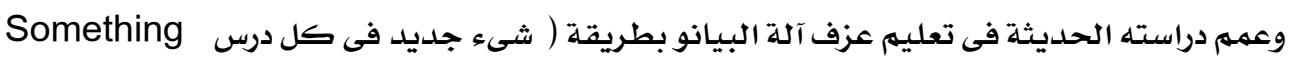

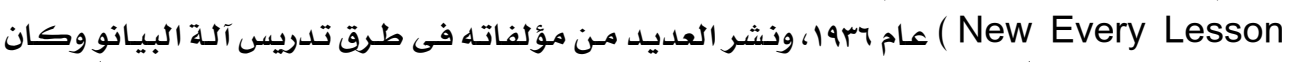

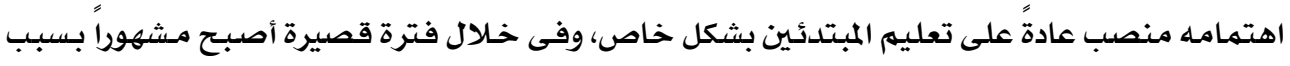
جهوده المخلصة لجذب الطلاب الصغار لمجال العزف آلة البيانو. توفى جون طومسون عام با194 لكن ظلت كتبـه وما تتتناوله من أسـلوب تريـوى شيق مـن أهـم

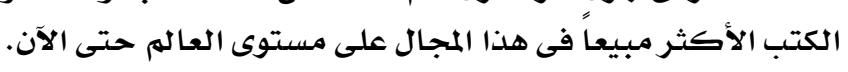

(http://www.willispianomusic.com/search/search.do?menuid=14328 $\&$ subsiteid=264\&\&searchtype=product \&resultsperpage=60, access date 04/04/2015) 
- - أسلوب جون طومسون فى تعليم مزف آلة البيانو:

يتسهم أسلوب جون طومسون ببعض السمات الهامـة التى تميز طابعه التربوى فى تعليم عزف

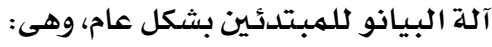

ا- تعليه المبتدى العزف على آلة البيانو بطريقة محببة ومشوقة منذ البداية من خلال استخدلامهـ

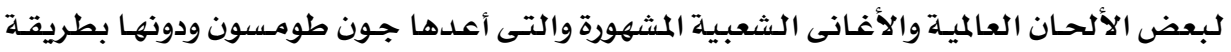

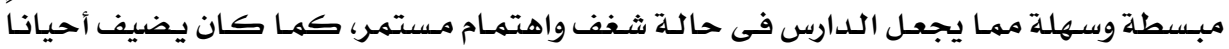

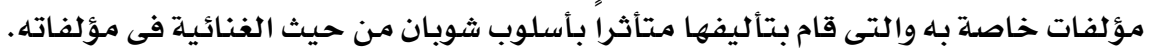

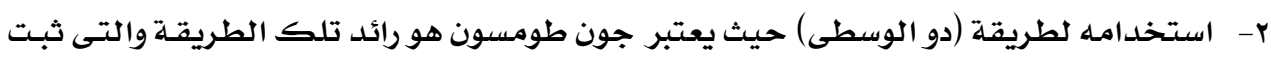
نجاحها فى تعليم عزف آلة البيانو. r- دم-ج أكثر من معلومة موسيقية نظريـة وعملية في آن واحد.

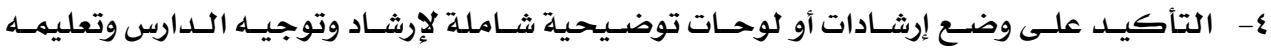

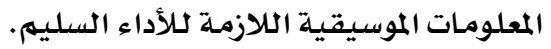

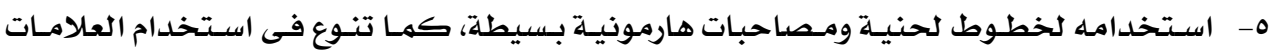
الإيقاعية المختلفة.

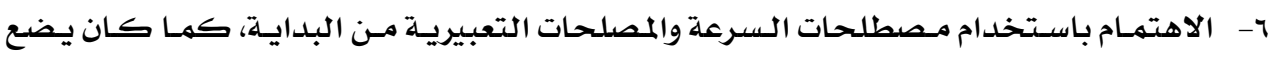
عنوان معبر لكل مقطوعة على حلده.

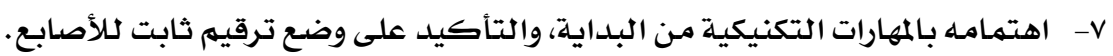

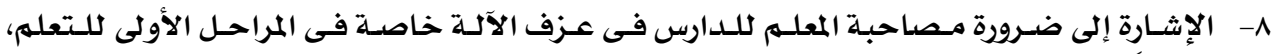

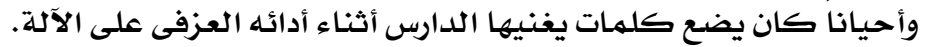

Easiest Piano Course

Teaching Little Fingers to Play

Christmas Piano Solo

First Christmas Duets

Modern Course for the Piano

First Grade Etudes - 24 studies

For Left Hand alone

Arizona Suite for Piano
- أهم أعمادــه: - - أسهل برنامـج لتعليهم البيانو تعليه العزف لذوى الأصسابع الصغيرة - معزوفات عيد الميلاد للبيانو المنفرد - ثنائيات البيانو الأولى لعيد الميلاد - - برنامـج حديث لتعليهم البيانو

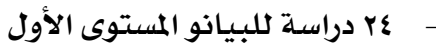
- كيد اليسرى بمفردها متتابعة أريزونا كلبيانو 
Five for Four "Five Duets for Four hands - one Piano"

Octave Book

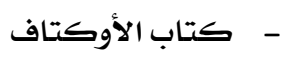

Melody All The Way

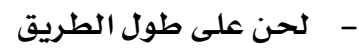
Adult Preparatory Piano Book - كتاب المستوى الأول التمهيدى لتعليم البيانو للكبار Popular Piano Solos - معزوفات البيانو المثهورة (الشعبية) Note-Speller Adult Piano Course - مراءة وكتابة النوتة الموسيقية First Classics - - - برنامجج البيانو لتعليه الكبار

Valse Chromatique الكلاسيكيات الأولى لئى First Disney Songs Accompaniment Book - كتاب المصاحبة -

(http://www.willispianomusic.com/search/search.do?menuid=14328 $\&$ subsiteid=264\&\&searchtype $=$ product\&resultsperpage $=60$, access date 04/04/2015)

\section{ثانياً: الإطار التطبيقى:}

يتناول هذا الجزء دراسـة أسلوب جون طومسون فى تعليم عزف آلـة البيانو للمبتدئين الكبـار

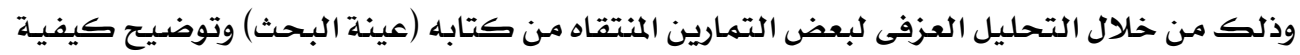

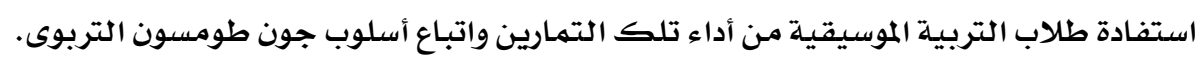
بدأ جون طومسون كتابه (المستوى الأول التمهيدى لتعليم البيانو للكبار) بالشرح من خلال التول

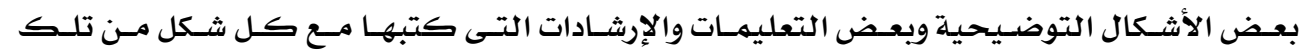

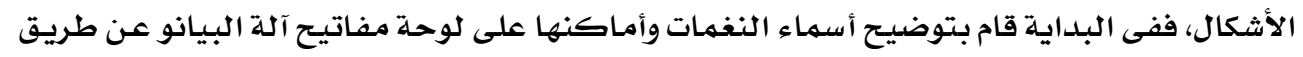

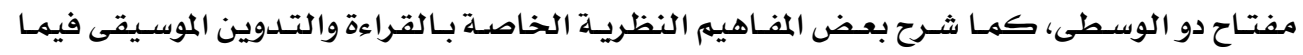

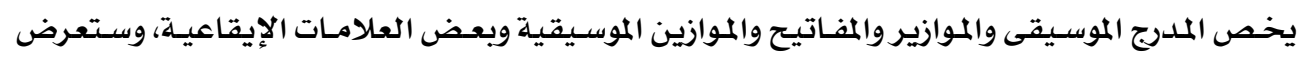

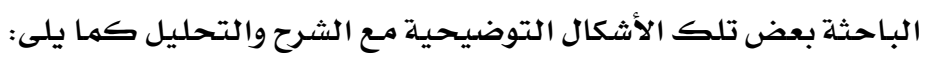

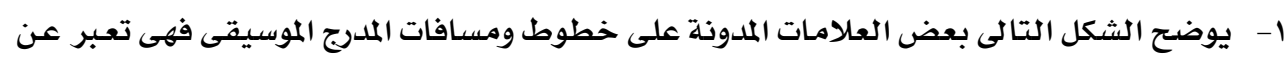

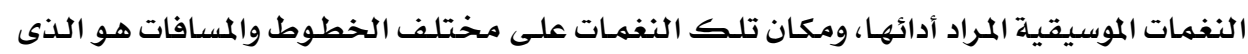

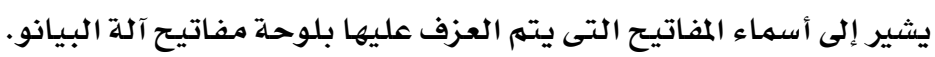


ב-

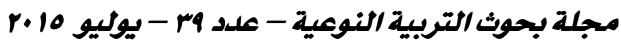

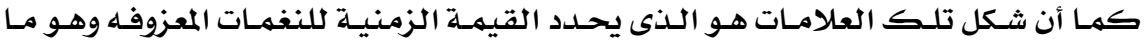
يعرف بإسهم الإيقاع، وعلى سبيل المثال:

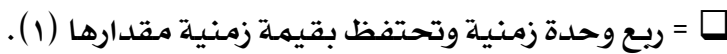

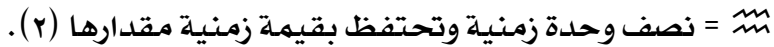

ه = وحدة زمنية كاملة وتحتفظ بقيمة زمنية مقدارها (ع ). إن الميزان الموسيقى الذى يدون فى بداية أى مقطوعة موسيقية هو الذى يعبر عن:

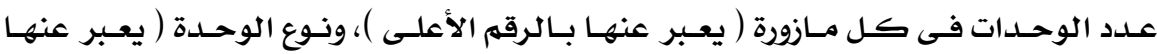
بالرقم الأسفل ).

Upper figure means that there are two counts to a measure.

Lower fiǵture means that each quarter-note gets one count.
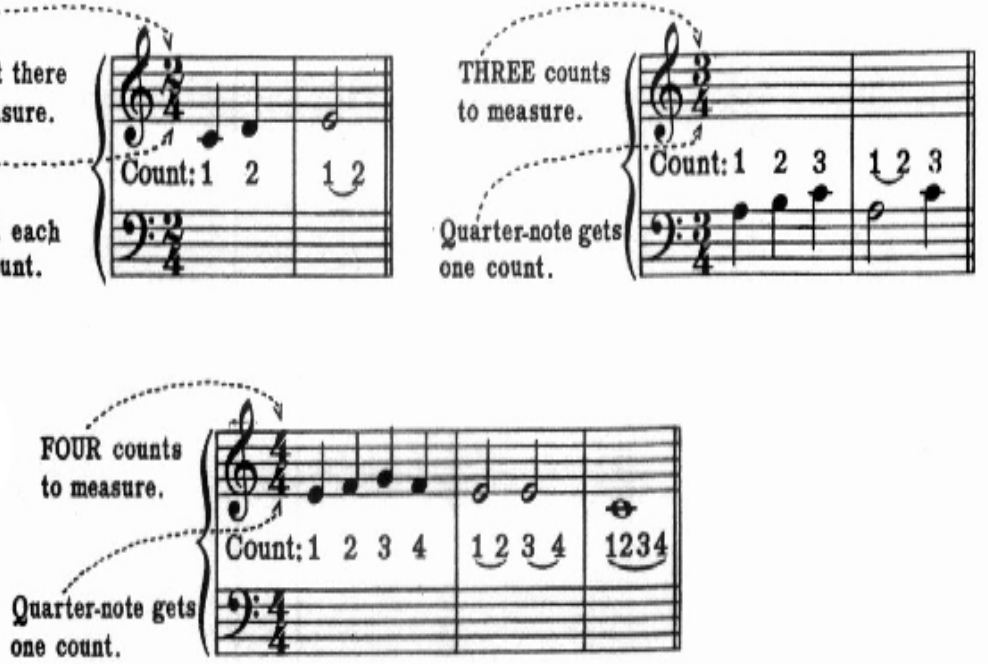

شكل رقم (1)

الموازين الموسيقية والعلامات الإيقاعية

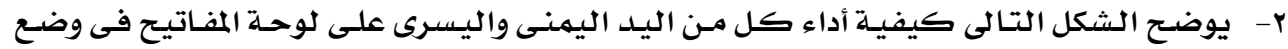

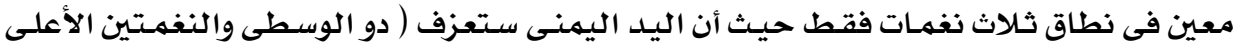
منها )، بينما ستعزف اليد اليسرى ( دو الوسطى والنغمتين الأسفل منها فئه ). 

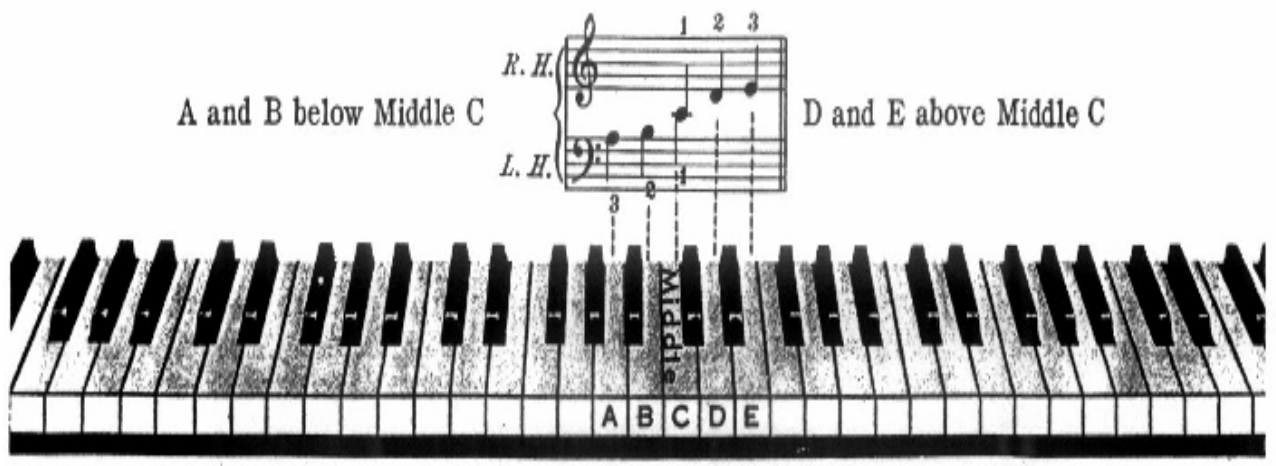

شكل رقم (r)

\section{أداء اليدين باستخدام الثلاث أصابع أعلى وأسفل دو الوسطى}

r- توضح الأثكال التالية بعض التمارين التى يبدأ بها الطالب العزف على آلـة البيـانو مـع الالتزام

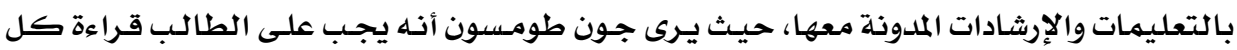

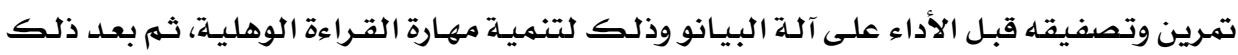

$$
\text { يقوم بعزفه على الآلة كمها هو مدون. }
$$

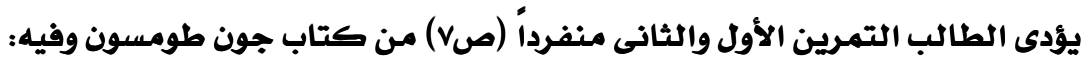

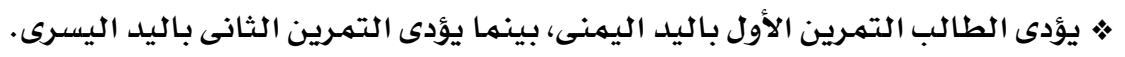

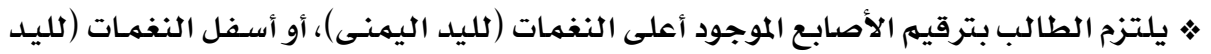

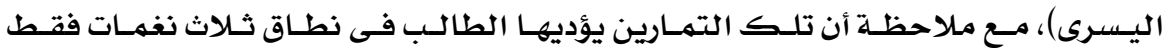

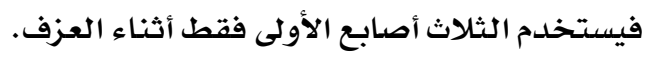

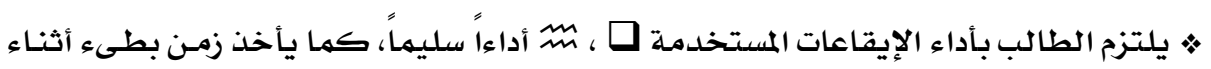

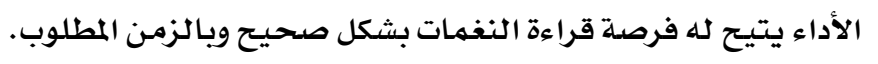

* يقوم الطالب فى بداية العزف برفع اليد لأعلى قلسيلاً ثم ينزل بالأصبع رقهم (1) على مفتاح

$$
\text { دو الوسطى. }
$$

ه يتجنب الطالب النظر إلى الأصابع والمفاتيح أثناء الأداء ويركز بالنظر إلى المدونة الموسيقية

$$
\text { التى يقوم بأدائها. }
$$

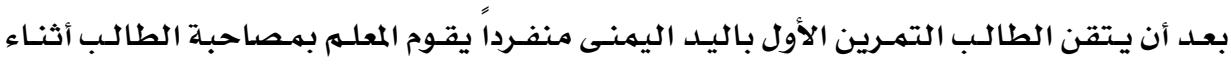

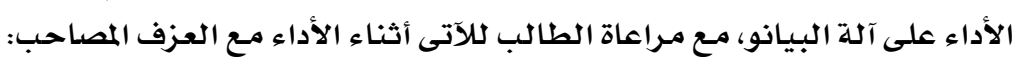

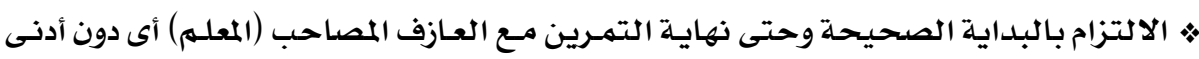

$$
\text { سبق أو تأخير أثناء الأداء. }
$$

• الالتزام أثناء الأداء بوحدة زمنية واحدة وبنفس السرعة مع العزف المصاحب. 


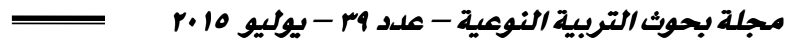

• الإحسـاس بالهارمونيات المصاحبـة وبتعبيراتها المختلفـة المدونـة عليها مـع السـماح بإظهار دور

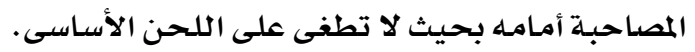

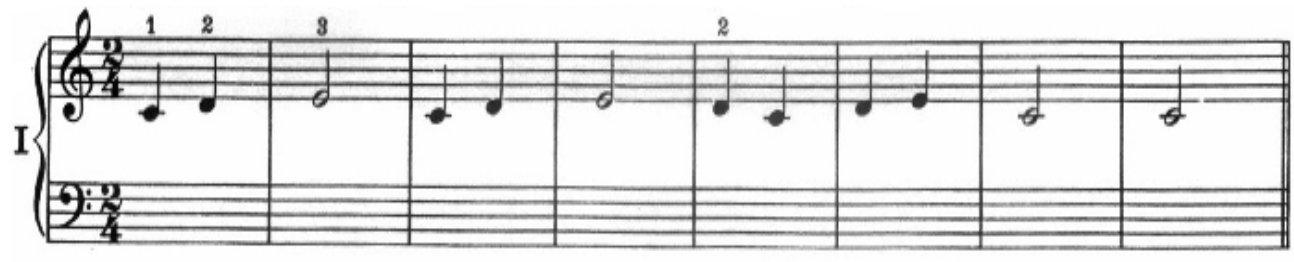

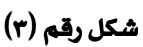

التمرين الأول لأداء اليد اليمنى صل من كتاب جون طومسون ( للطالب )

Played by Teacher

Accompaniment to No. 1 on opposite page

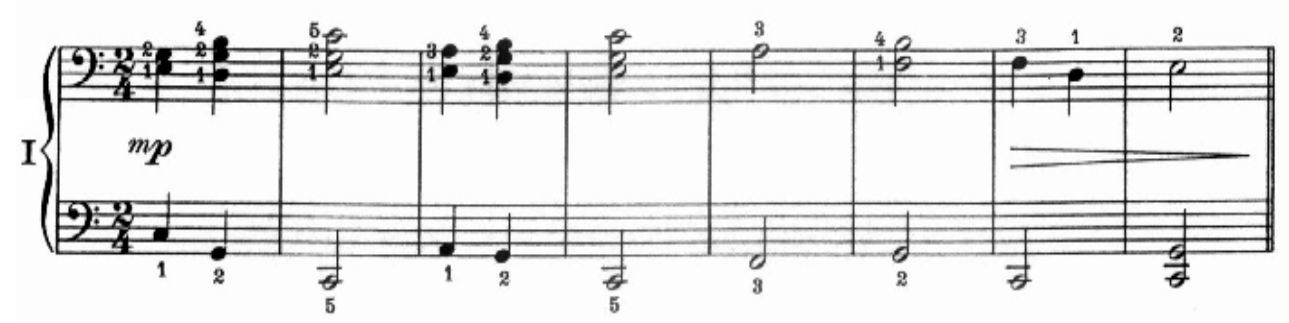

شكل رقم (£)

مصاحبة التمرين الأول صף من كتاب جون طومسون ( للمعلم )

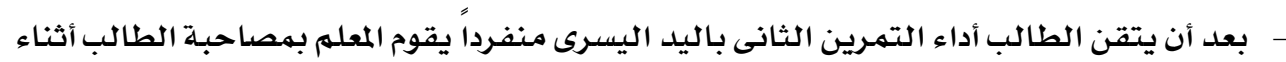

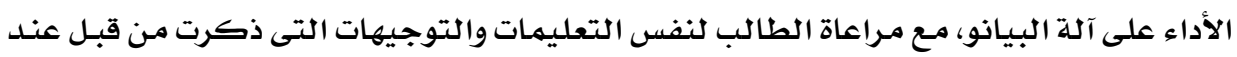
مصاحبة التمرين الأول.

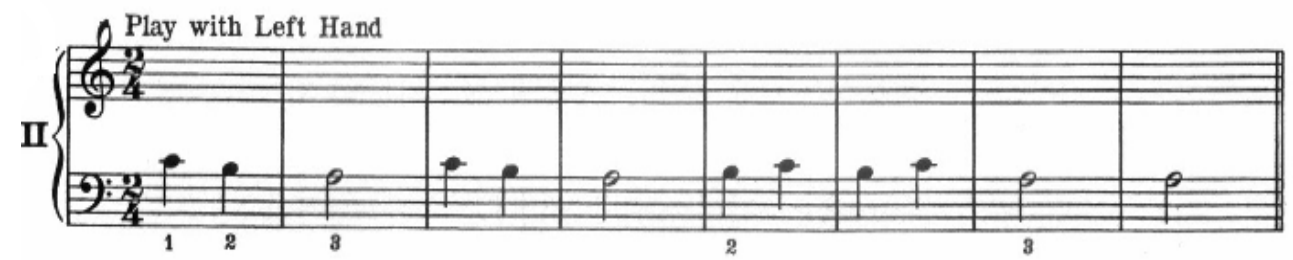

(0) شكل رقم (0)

التمرين الثانى لأداء اليد اليسرى صV من كتاب جون طومسون ( للطالب ) (ه) 
Accompaniment to No. 2 on opposite page

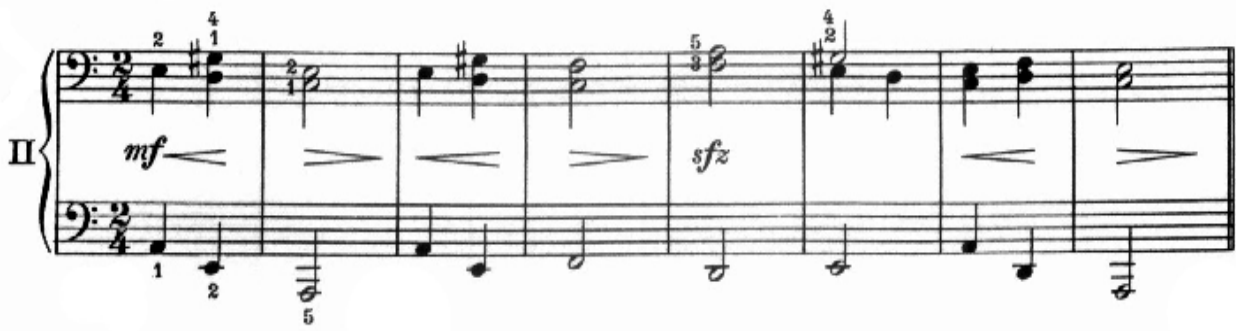

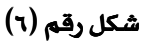

مصاحبة التمرين الثانى صף من كتاب جون طومسون ( للمعلم )

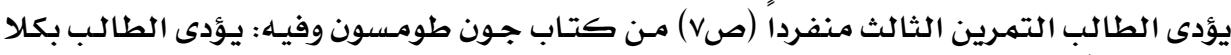

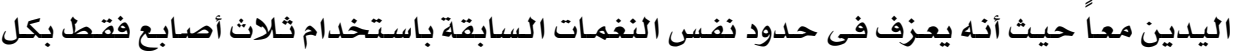

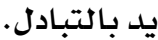

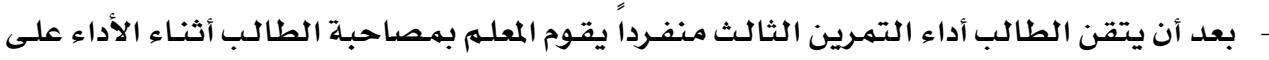

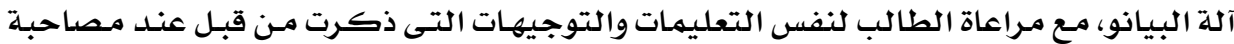

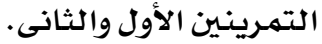

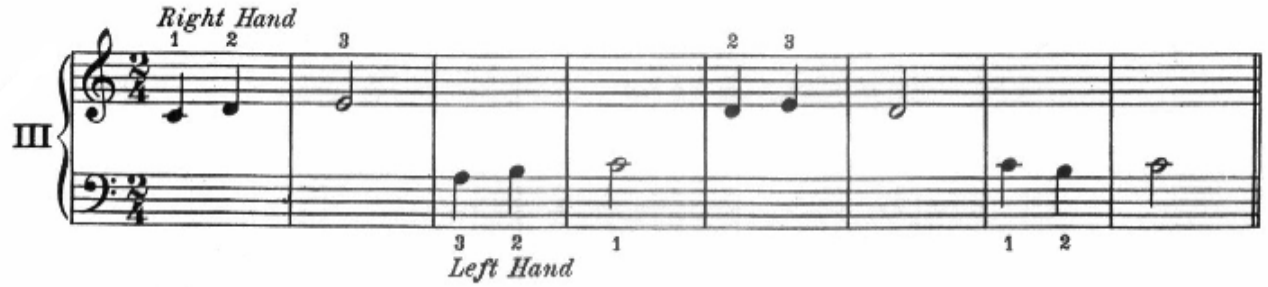

شكل رقم (v)

التمرين الثالث لأداء اليدين معاً صل من كتاب جون طومسون ( للطالب )

Accompaniment to No. 3 on opposite page

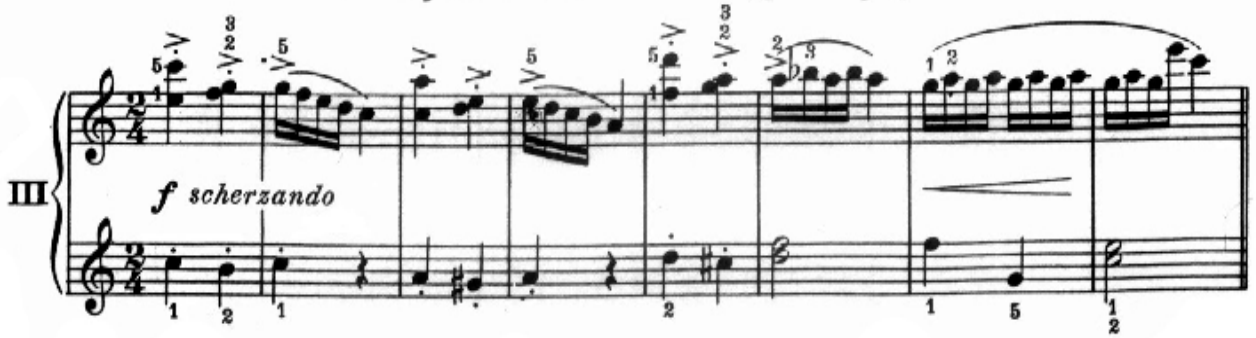

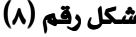

مصاحبة التمرين الثالث صح من كتاب جون طومسون ( للمعلم ) 


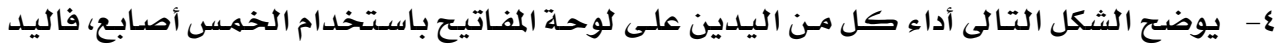

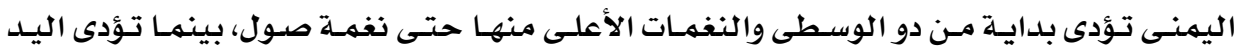

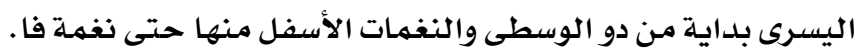

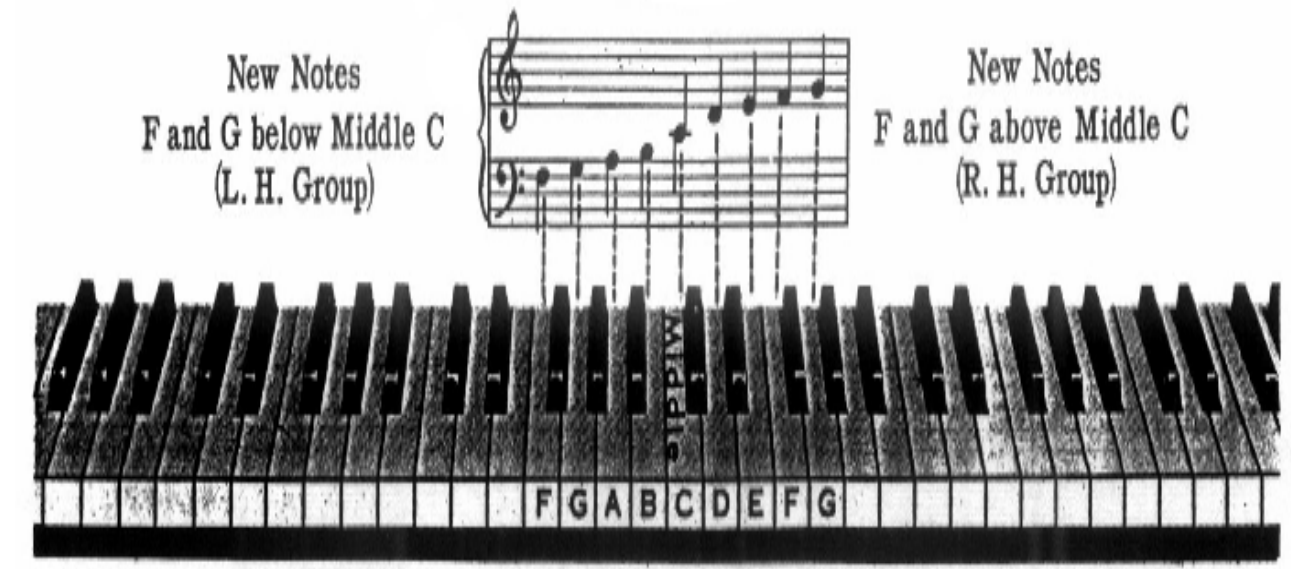

(a) شكل رقم (a)

أداء اليدين باستخدام الخمس أصابع أعلى وأسفل دو الوسطى لوفى

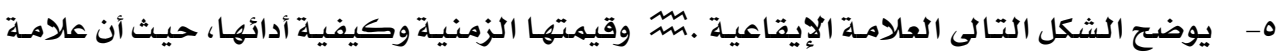

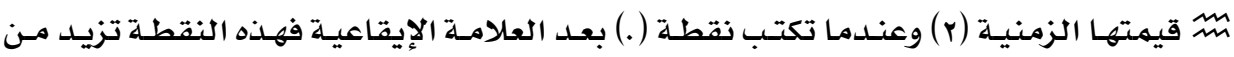

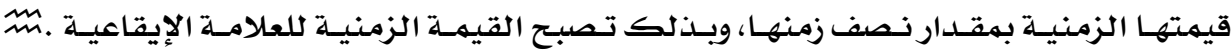
هى (r)

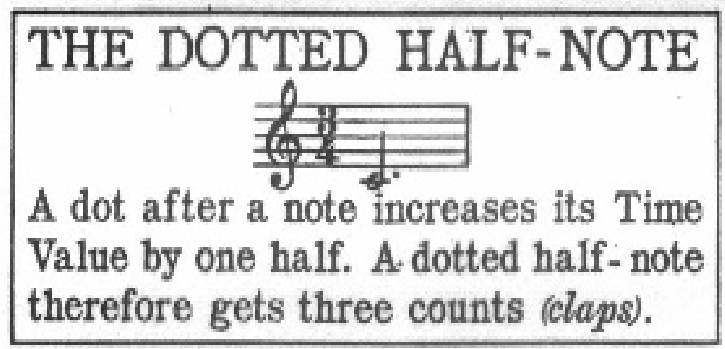

شكل رقم (.)

m. القيمة الزمنية للعلامة الإيقاعية

1- يوضـح الشكل التالى بعض السكتات وقيمها الزمنية، حيث أن لكل علامسة إيقاعية سكتة لها شكل

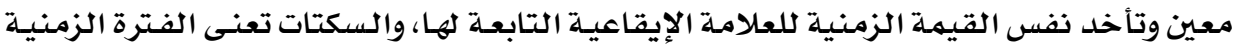

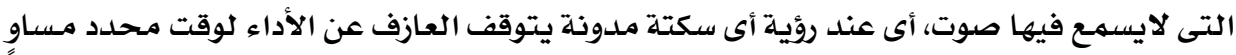
لقيمتها الزمنية. 


\section{REST SIGNS}

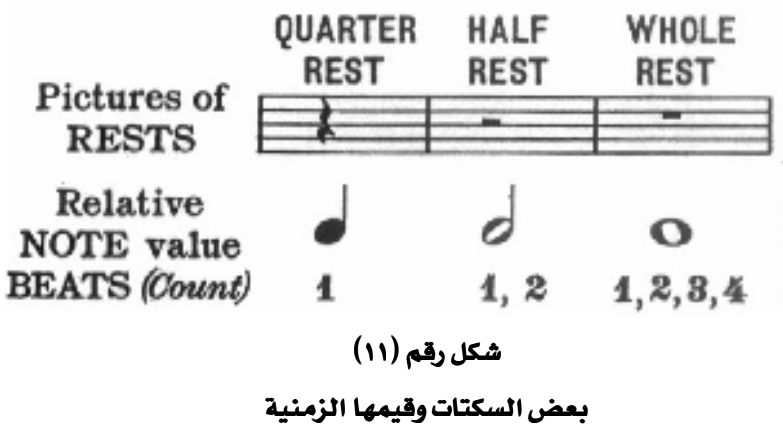

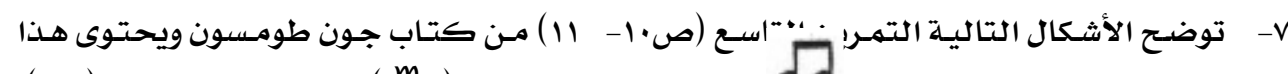

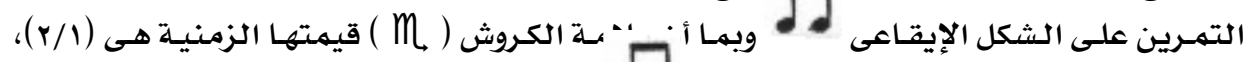

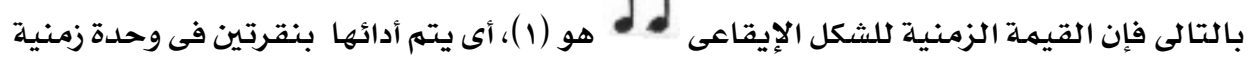

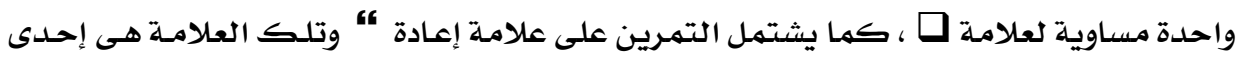

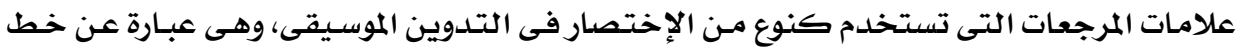

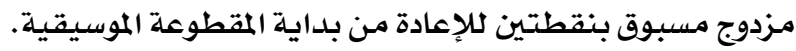

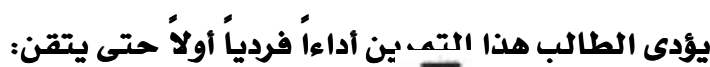

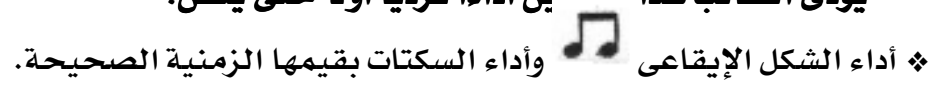
م. أداء النغمات المتكررة والنغمات المدونة على مسافة الثالثة الصاعدة والهابطة بشكل سليه.

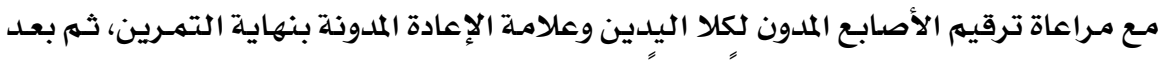
ذلك يقوم الطالب بأداء نفس التمـرين أداءاً ثنائياً مـع المعلهم.

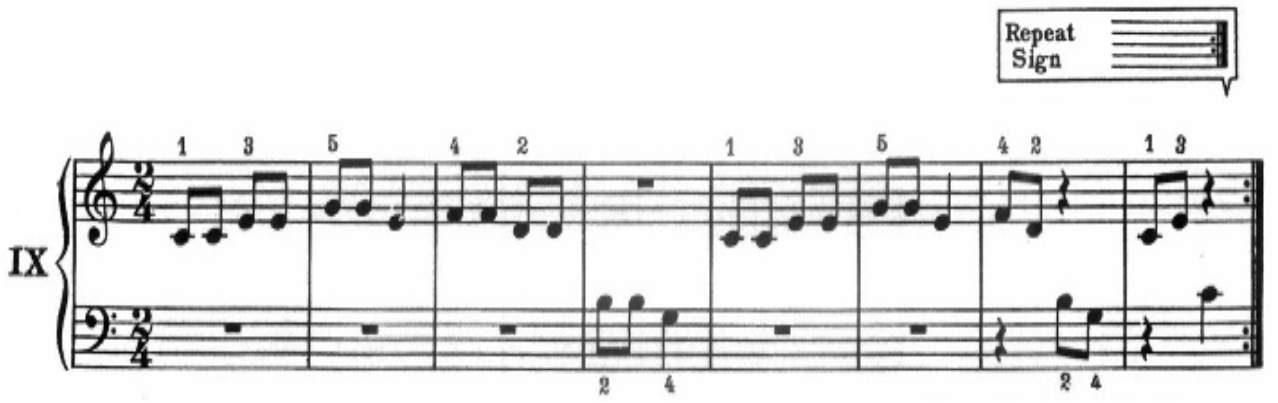

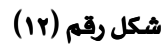

التمرين التاسع ص|| من كتاب جون طومسون ( للطالب ) 


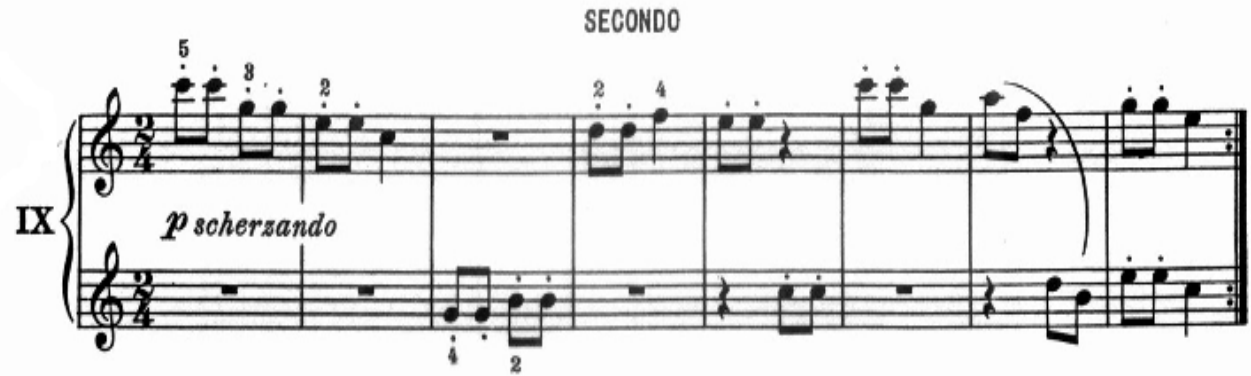

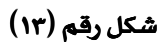

الصوت الثانى للتمرين التاسع ص.1 من كتاب جون طومسون ( للمعلم )

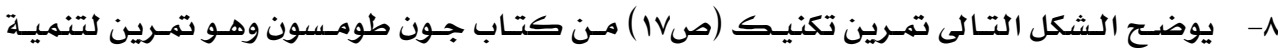

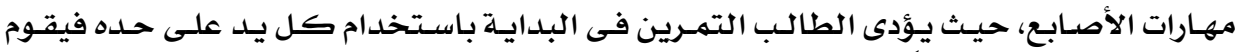

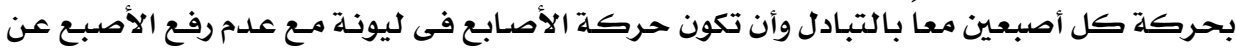

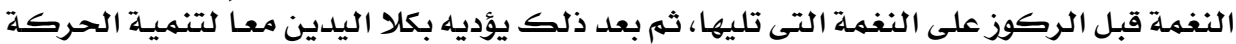

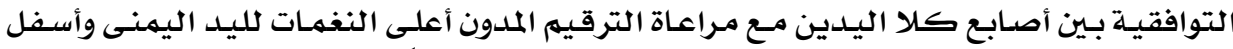

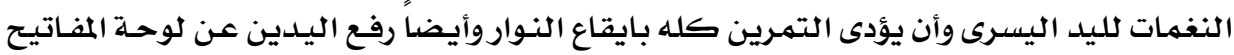

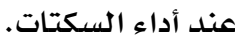

\section{FINGER DRILL}

First each hand separately then hands together, one octave apart.
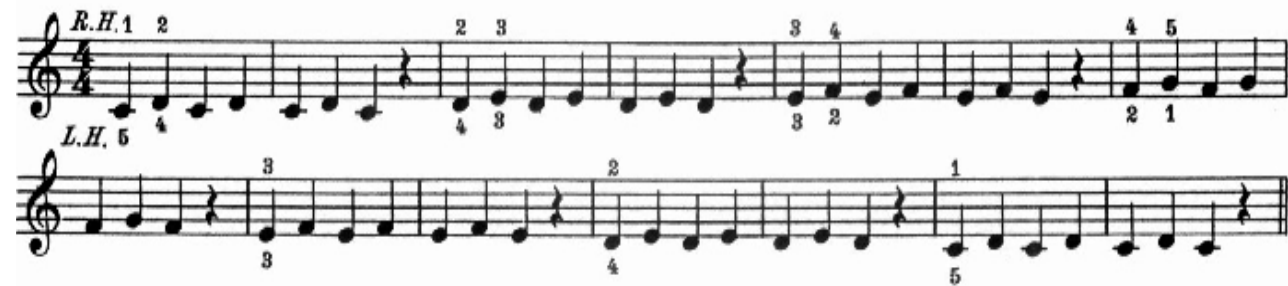

شكل رقم (1\&)

تمرين تكنيك صلا من كتاب جون طومسون

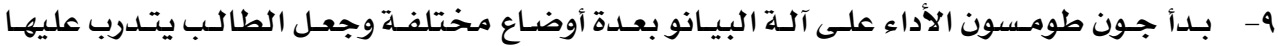

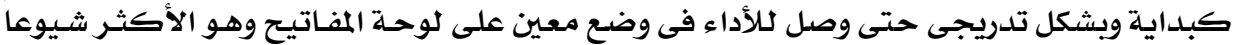

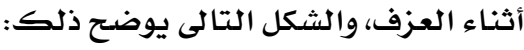




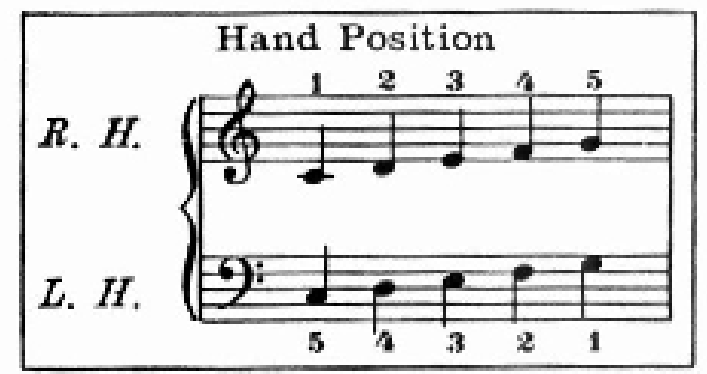

شكل رقم (10)

\section{وضع اليدين على لوحة مفاتيح آلة البيانو}

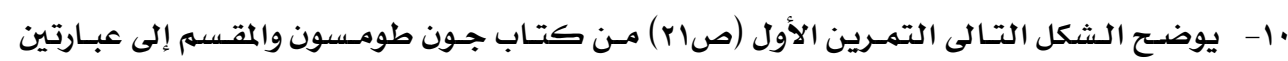

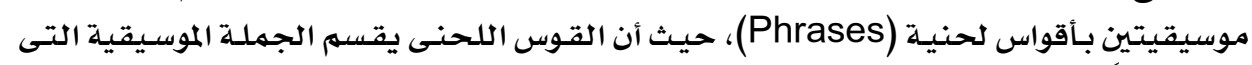

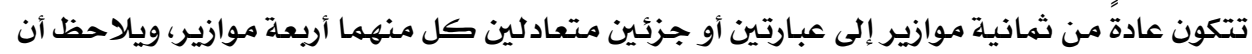

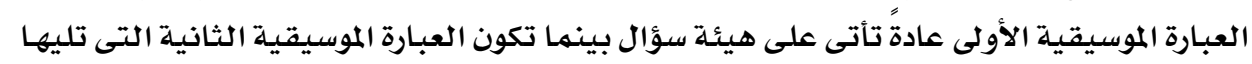

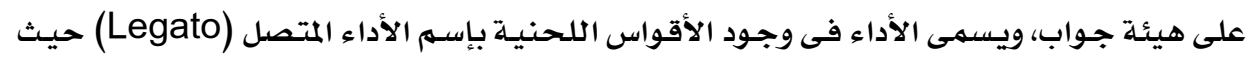

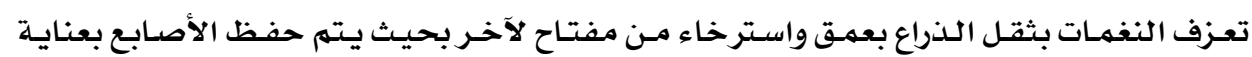

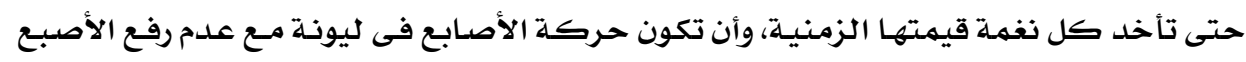

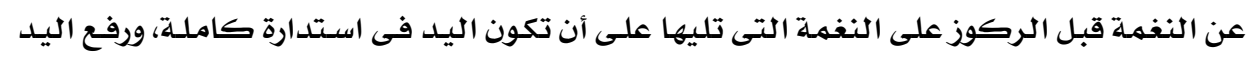

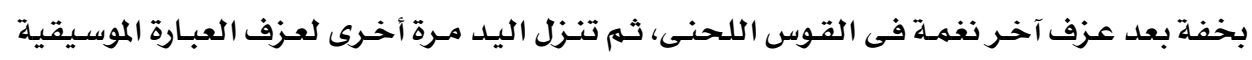

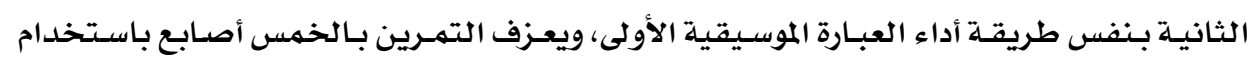
العلامات الايقاعية (البلانث والروند) في كلتهاء الديل اليدين.

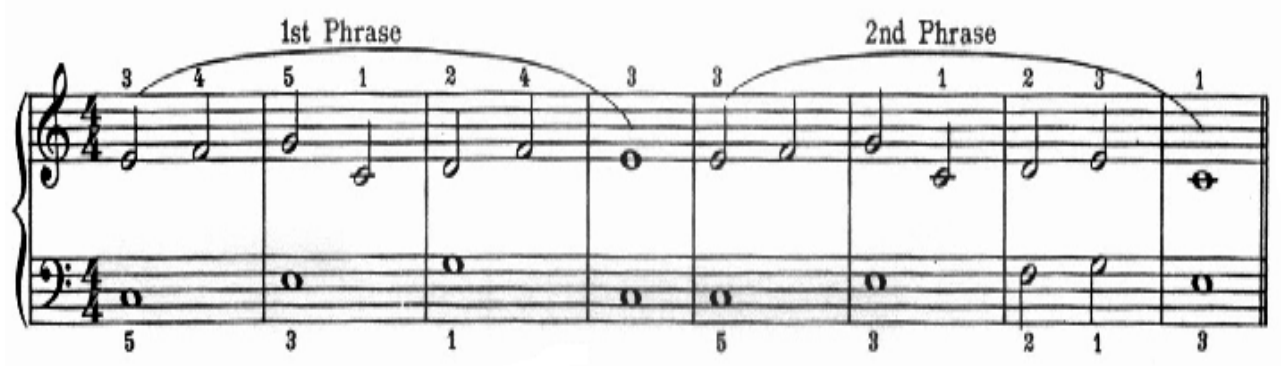

شكل رقم (19)

تمرين صاr من كتاب جون طومسون لأداء القوس اللحنى (Phrase)

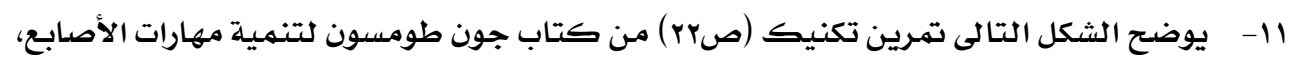

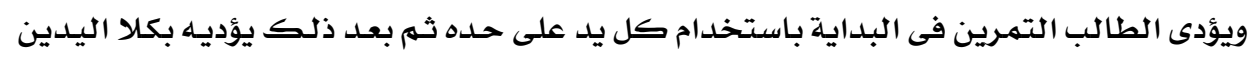




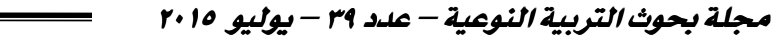

معاً لتنـمية الحركة التوافقية بـين أصابع كلتا اليدين، مـع مراعاة الترقيم الملدون أعلى النغمـات لليد اليمنى وأسفل النغمات لليد اليسرى.

ويتناول هذا التهـرين نهوذج لحنى مكرر يؤديه كل س أصسابع مـع بعضهم البعض مـع مـراعـاة أن النهموذج يبـدأ مـن نغمهة مـختلفـة كل مـرة عند تكراره، ثم يعيــ الطالب أداء التمـرين مـرة أخـرى مـن بدايته لوجود علامـة الإعادة المدونة بنهاية التمـرين. ويعتبر هذا التمـرين بهثابـة تههيـد للمقطوعـة الموسيقية التى سيقوم الطالب بأدائها فيمـا بعد حيث أنها تحتوى على نفس النهموذج اللحنى أو نفس التيهـة الموسيقية الموجودة فى التهـرين.

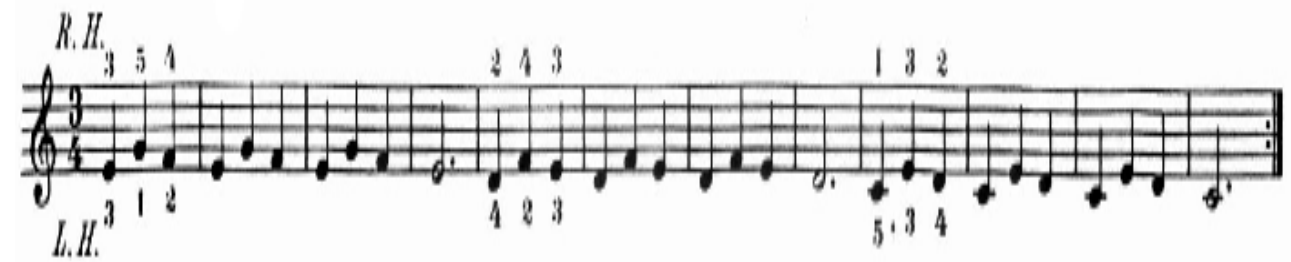

$$
\text { (iv) شكل رقم (1) }
$$

\section{تمرين تكنيك صوr من كتاب جون طومسون}

با - إن التبـاين هـو القـانون الأول لجميـع أنـواع الفنـون، ومـن أهـم الأثـياء التى تظهـر ذلك التبـاين والتفاوت هو مـا يعرف بإسهم التظليل الصوتى والذى يعبر عنـه بالعديــ مـن المصطلحسات التعبيريـة المدونة (وهى تُدون بحـروف كنـوع مـن الاختصـار) والتى لكل منهها معنى يـدل على كيفيـة الأداء بحس جمـالى مختلـف، وستوضـح الأثـكال التاليـة أن جـون طومسسون قـام بعـرض أشـكال التظليـل الـصوتى وكيفيـة أداء تلـك المصطلحات التعبيريـة الخاصسة بهـا مـن خـلال مقطوعـة موسـيقية

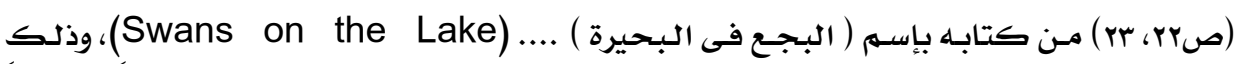
لتتهيـة التذوق والحس الجِمالى لدى الطالب وجعل أدائه على آلتة البيانو أكثر استمتاعاً وتشويقاً وبذذك يكون أكثر إقبالاً على دراستها. تُعزف تلك المقطوعة الموسيقية فى سلهم دو الكبير وهى تتناول نفس فكرة النموذج اللحنى الموجود

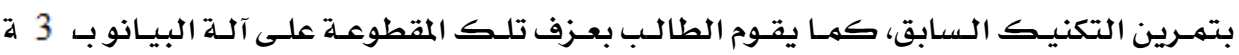

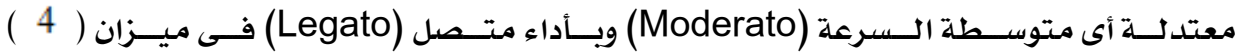
وباستخدلام العلامات الإيقاعية ( .

تنقسهم تلك المقطوعـة إلى (ع) جمل موسيقية وكل جملـة مكونه مـن (^) مـوازير ومقسهمة

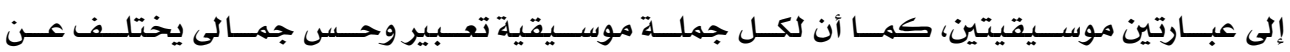
الجمللة الأخرى.

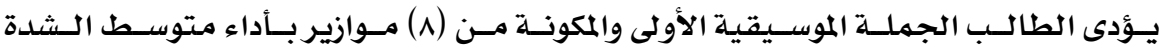

أو القوة (mf). 
Swans on the Lake
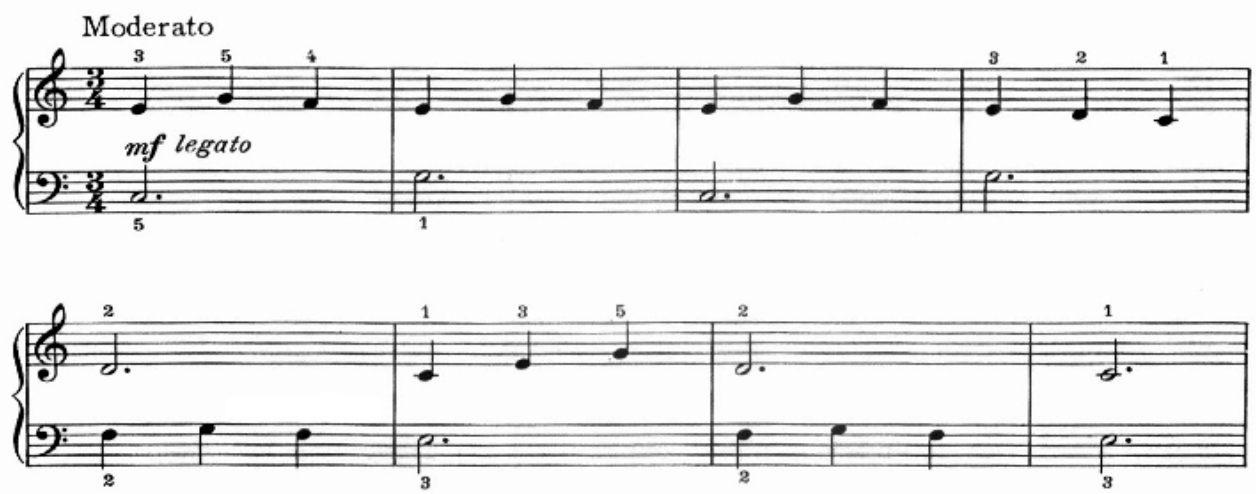

شكل رقم (11)

الجملة الأولى من المقطوعة الموسيقية (Swans on the Lake)

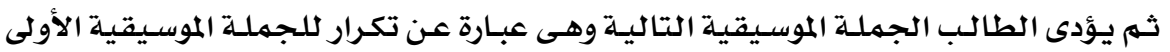

لكنها تُؤدى بصوت خافت (P))، وذلك للإحساس بنفس الجملة الموسيقية بتعبير مختلف.
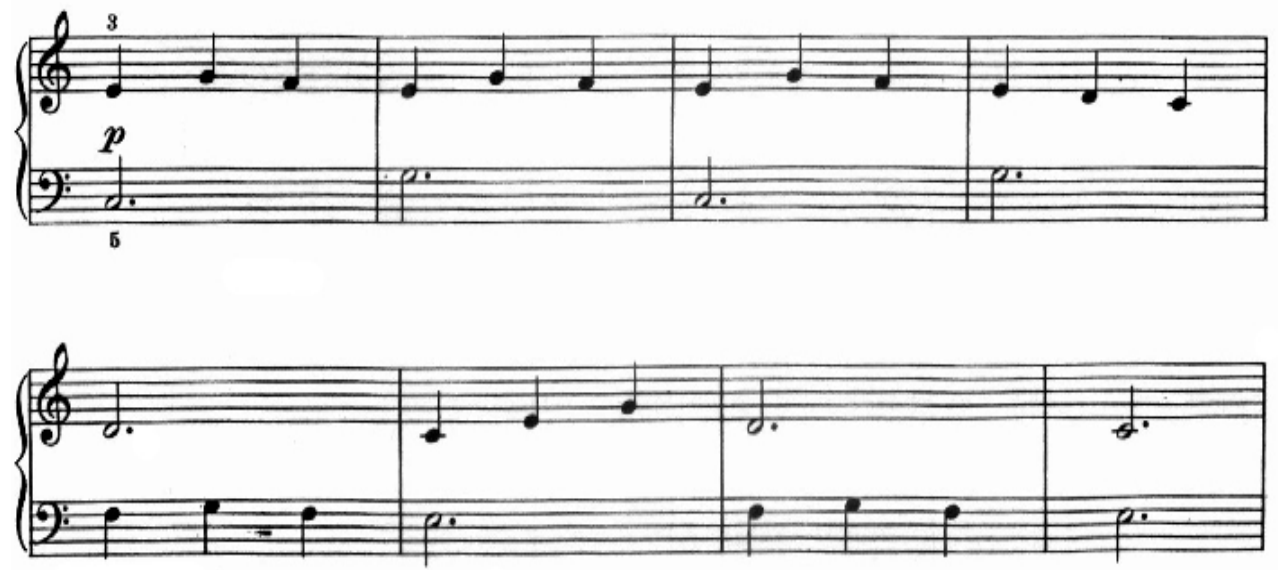

شكل رقم (19)

الجملة الثانية من المقطوعة الموسيقية (Swans on the Lake)

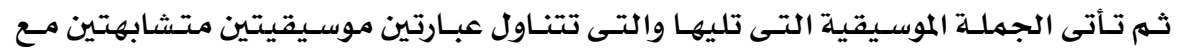

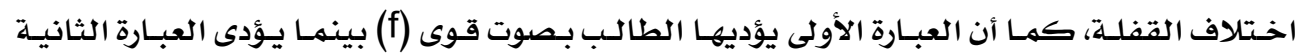

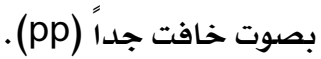



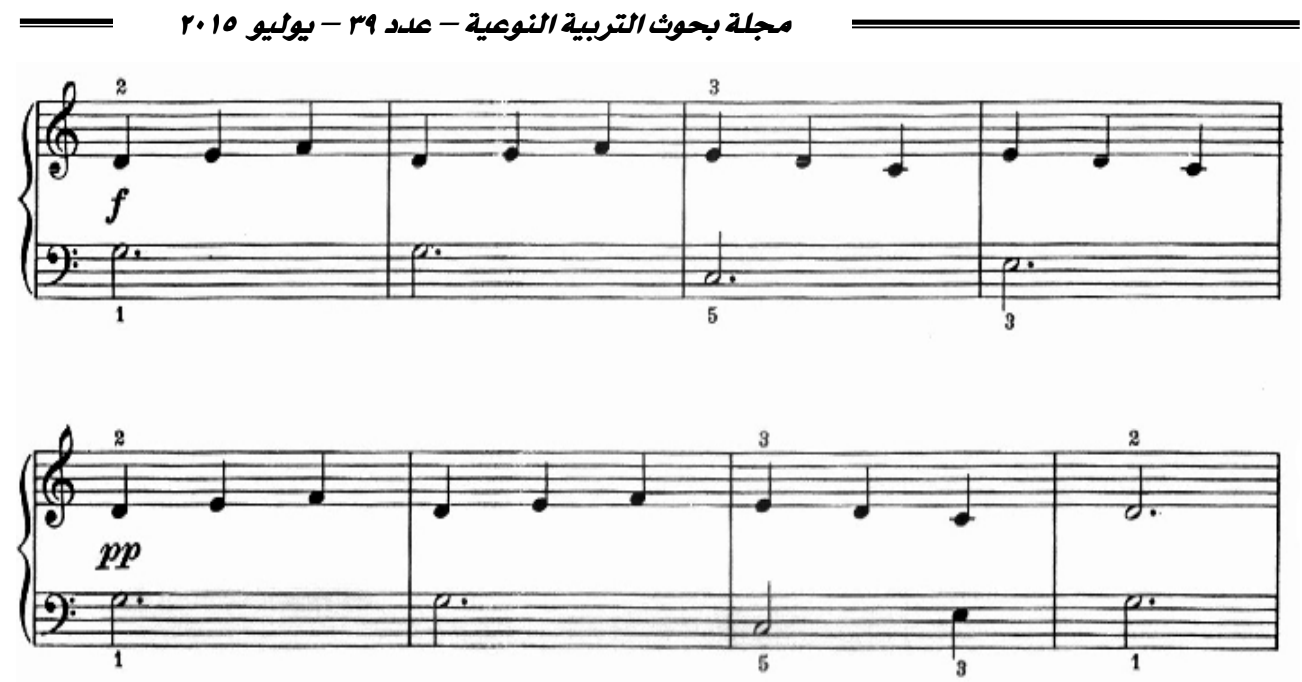

(r.) شكل رقم (r)

الجملة الثالثة من المقطوعة الموسيقية (Swans on the Lake)

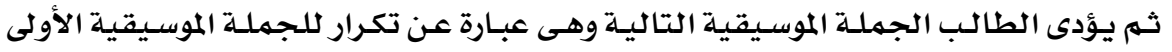

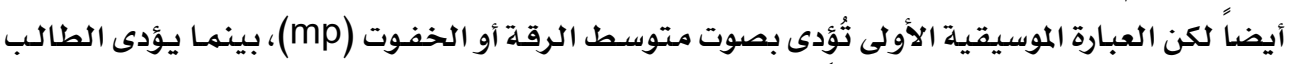
آخـر (r) مــوازيـر بــوت خافت جــاً (pp)، مـع تـأخر تـدريجى فـى الســرعة (.rit) فـى آخـر مـازورتين (القفلة).
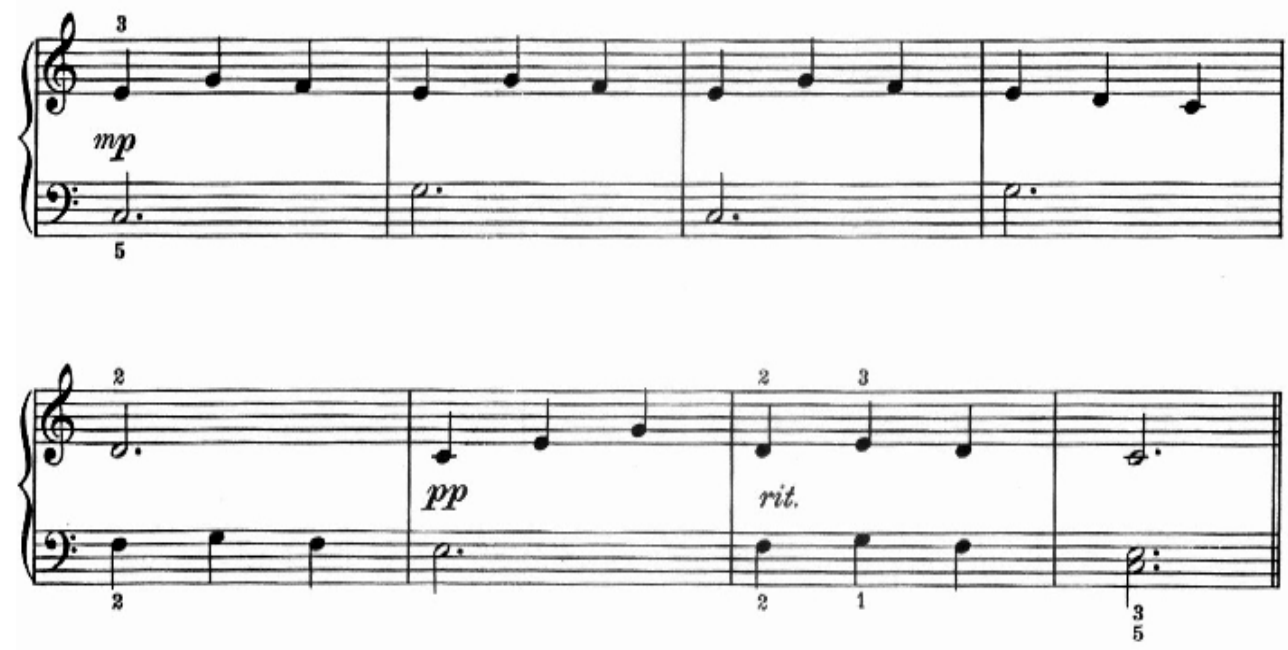

شكل رقم (ri)

الجملة الرابعة من المقطوعة الموسيقية (Swans on the Lake) 
ولقد وضح جون طومسون معانى جميع المصطلحات التعبيرية التى تناولتها تلك المقطوعة

الموسيقية ووضعها أسفل المقطوعة كما فى الشكل التالى:

\begin{tabular}{|l}
\hline THE MEANING OF THE EXPRESSION MARKS USED IN THIS PIECE \\
MODERATO - At a moderate rate of speed. \\
LEGATO - Bound together, smoothly connected. \\
$m \boldsymbol{f}=$ MEZZO FORTE - Moderately loud. \\
$\boldsymbol{p}=$ PIANO - Softly. \\
$\boldsymbol{f}=$ FORTE - Loud. \\
$\boldsymbol{p} \boldsymbol{p}=$ PIANISSIMO - Very soft. \\
$m \boldsymbol{p}=$ MEZZO PIANO - Moderately soft. \\
$r i t .=$ RITARD. - Gradual slowing up of tempo.
\end{tabular}

شكل رقم (rr)

معانى المصطلحات التعبيرية المستخدمة فى المقطوعة الموسيقية (Swans on the Lake)

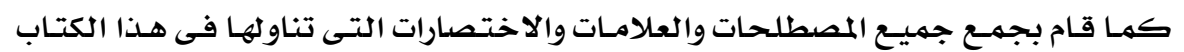

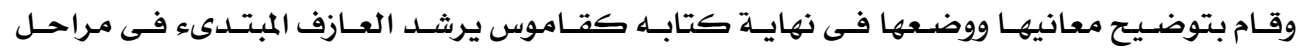
أدائه المختلفة.

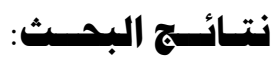

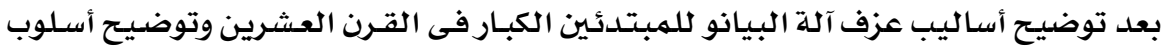

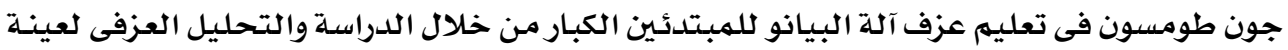
البحث توصلت الباحثة إلى النتائج التالية:

1- تحديد بعض أساليب تعليهم عزف آلة البيانو للمبتدئين الكبار فى القرن العشرين وأهـم مـا يميـز

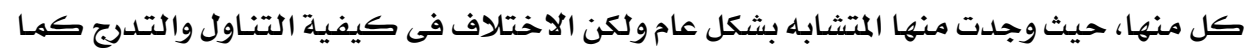

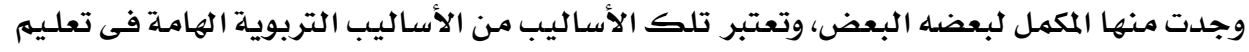

$$
\text { عزف آلة البيانو. }
$$

r- ت تحديد أسلوب جون طومسون فى تعليم عزف آلة البيانو للمبتدئين الكبار حيث تميز بأنه: بدأ تعليهم آلة البيانو بتوضيح أسماء النغمات وأماكنها على لوحة مفاتيح آلة البيانو عن

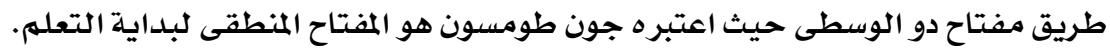

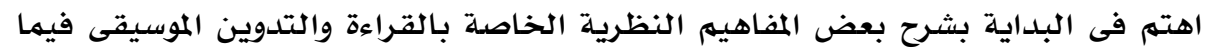

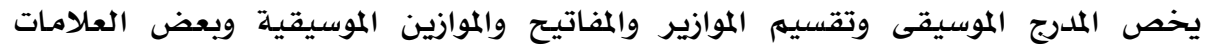
الإيقاعية البسيطة. 
جعل الدارس فى البداية يؤدى بكل من اليد اليمنى واليد اليسرى فى نطاق الثلاث نغمات

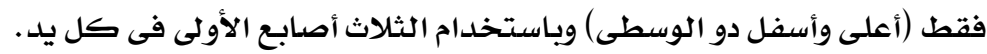

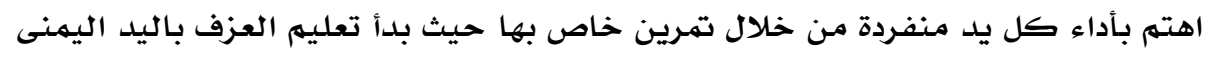

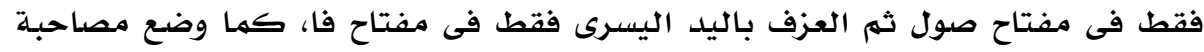

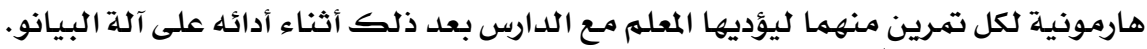

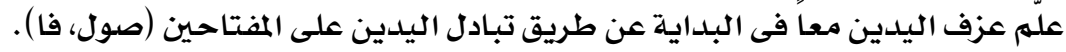

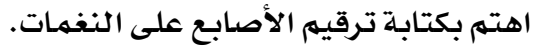

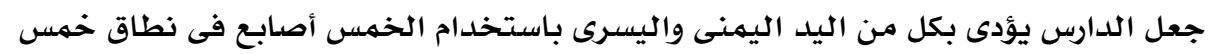
نغمات أعلى وأسفل دو الوسطى.

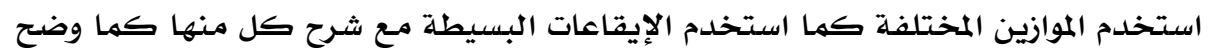

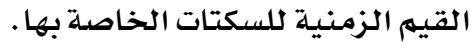

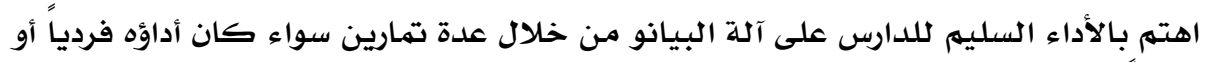

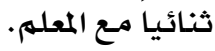
اهتم بتنمية مهارات الأصابع من خلال أداء بعض التماتمارين التكنيكية البسيطة.

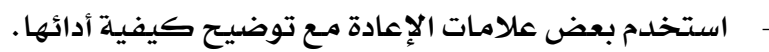

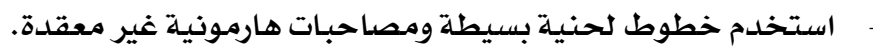

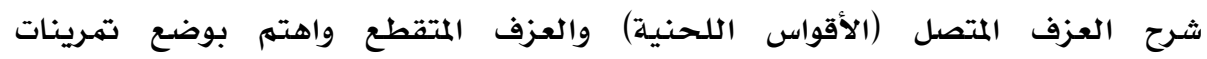
للتدريب عليهما. بدأ التدريب فى سلهم دو الكبير ثم انتقل إلى سلهم صول الكبير، كما أنه اهتم بشرح السلالم

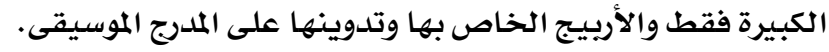

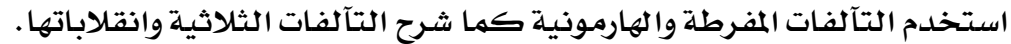

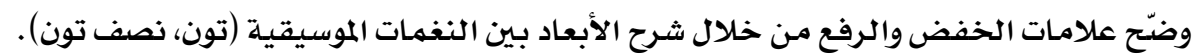

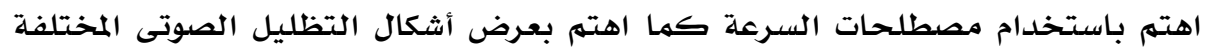

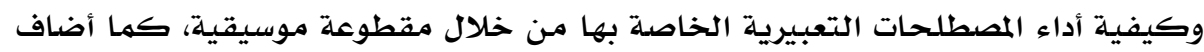

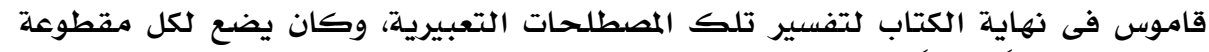

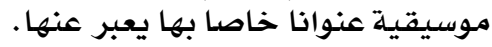

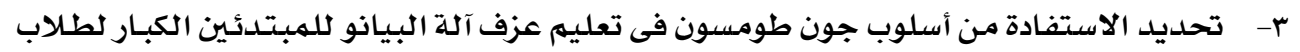

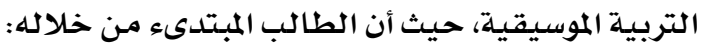
يستطيع أن يتعلم العزف على آلة البيانو بطريقة محببة ومشوقة منذ البداية لأن جون

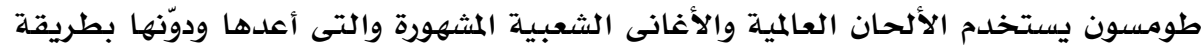

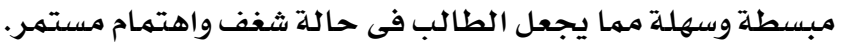


يستطيع أن يتعلم بأسلوب تريوى لأن أسلوب جون طومسون يتميز بالتدرج من السهل إلى

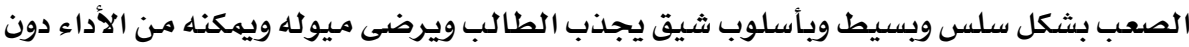

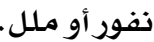
يستطيع أن يتعلم أكثر من معلومـة موسيقية نظرية وعملية فى آن واحد. .

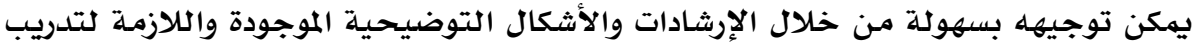
الطالب وأدائه بشكل سليه.

يستطيع أن ينهى مهارات الأصابع بالتدريب على التمارين التكنيكية المدونة.

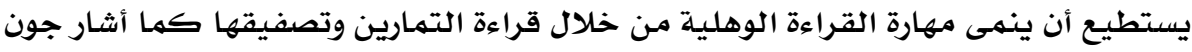
طومسون لذلك قبل ادائها على آلة البيانو.

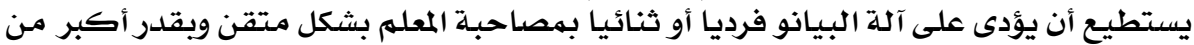
المتعـة والثقة بالنفس.

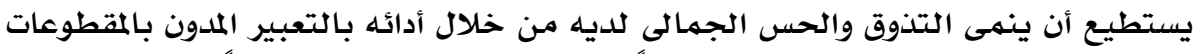

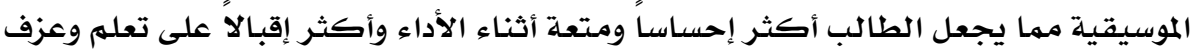
آلة البيانو.

\section{توصيسات البحث:}

فى ضوء ما أسفرت عنه نتائج هذا البحث، تقترح الباحثة التوصيات الآتية:

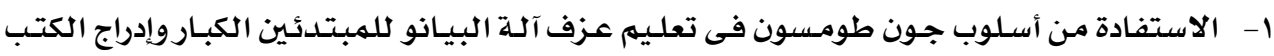
الخاصدة به ضمن برنامج عزف البيانو لطلاب كليات وأقسام التربية الموسيقية المبتدئين. r- استكمال مكتبة الكليـات الموسيقية بالكتب الخاصـة بأسـاليب تعليم عزف آلـة البيـانو للمبتدئين

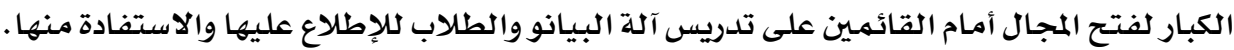

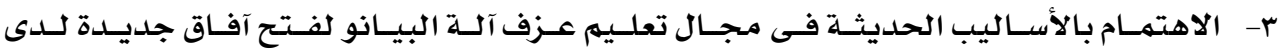
المعلمـين والدارسين.

ا- أحمد بيومى (Y991): القاموس الموسيقى، وزارة الثقافة المصرية، المركز الثقافى القومى، دار الأوبرا المصريـة، القاهرة. ץ- آمال صـادق - فؤاد أبو حطب (.199): علم النفس التربوة، الطبعة الثالثة، مكتبة الأنجلو المصرية، القاهرة.

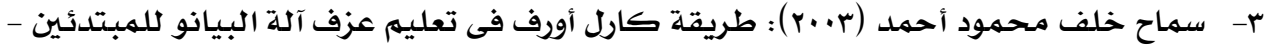

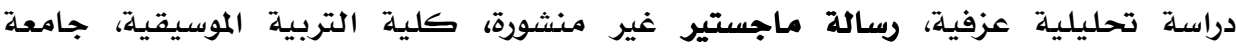
حلوان، القاهرة. 


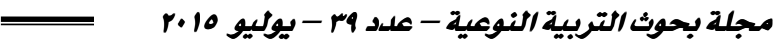

ع- سوزان أحمد عسل (1991): دراسة مسحية لتعليم آلة البيانو للمبتدئين الكبار، بحث منشور،

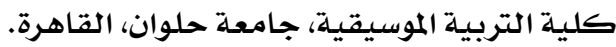

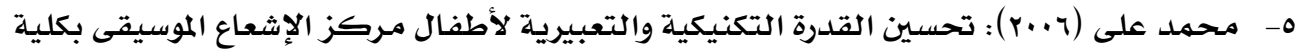

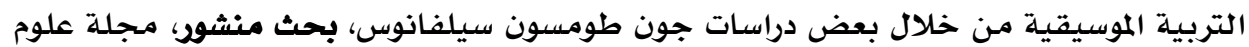

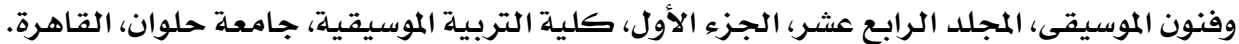

6- Aaron, Michael (1947): Michael Aaron Adult Piano Course, Belwin Mills, New York, U.S.A.

7- Cooper, Martin (1975): The Concise Encyclopedia of Music and Musician, Hutchinson \& Co (publishes) London.

8- Dibble, Cameron Shawn (1992): John Sylvanus Thompson: Pianist, Pedagogue, Composer, D.M.A., University of Missouri, Kansas City, U.S.A.

9- Thompson, John (1943): The Adult Preparatory Piano Book, The Wills Music Co., Cincinnati, Ohio, U.S.A.

$10-$

http://www.willispianomusic.com/search/search.do?menuid=14328\&subsiteid= $\underline{264 \& \& \text { searchtype }=\text { product } \& \text { resultsperpage }=60 \text {,access }}$ date 04/04/2015 
$-$ ב- أسلوب جون طومسون فى تعليم عزف آلة البيانو للمبتدئين الكباروالاستفادة منه لطلاب التربية الموسيقية

\section{The Style of John Thompson in teaching Piano for the Adult beginners and benefiting from it for Music Education Students}

\section{Abstract}

The researcher presents this research to find a scientific artical study that may contribute in finding the best style in teaching piano for the adult beginners to improve the music education students' performing level. That's because it helps to gain the skills of performance easily and gradually in an enjoyable way according to their abilities and desires. That's by clarifying some styles of teaching piano for the adult beginners in the 20th century, and the study and the analysis of John Thompson's style in teaching piano for the adult beginners and show the benefit of this to the music education students.

The researcher chose the sample of the research: some selective and fixed exercises from John Thompson's book (The Adult Preparatory Piano Book). The researcher followed the descriptive approach (content analysis).

\section{The researcher got to the following results:}

1- The researcher determined some of the styles in teaching piano for the adult beginners in the 20th century and the most important features for every one of them.

2- The researcher determined the style of John Thompson in teaching piano for the adult beginners by the study and performative analysis for the sample of this research.

3- The researcher determined the benefit of John Thompson's style in teaching piano for the adult beginners to the music education students. 